Eduard Shantsila

Gregory YH Lip

Non-Vitamin K

Antagonist Oral

Anticoagulants

A Concise Guide

$\triangle$ Adis

Springer Open 


\section{Non-Vitamin K Antagonist Oral Anticoagulants}



Eduard Shantsila $\bullet$ Gregory YH Lip

\title{
Non-Vitamin K \\ Antagonist Oral \\ Anticoagulants
}

\author{
A Concise Guide
}


Eduard Shantsila

University of Birmingham

Institute of Cardiovascular

Sciences

City Hospital

Birmingham

UK
Gregory YH Lip

University of Birmingham

Institute of Cardiovascular

Sciences

City Hospital

Birmingham

UK

ISBN 978-3-319-25460-9 (eBook)

DOI 10.1007/978-3-319-25460-9

Springer Cham Heidelberg New York Dordrecht London

(C) The Author(s) 2016

The book is published with open access at SpringerLink.com

OpenAccess This book is distributed under the terms of the Creative Commons Attribution Noncommercial License which permits any noncommercial use, distribution, and reproduction in any medium, provided the original author(s) and source are credited.

All commercial rights are reserved by the Publisher, whether the whole or part of the material is concerned, specifically the rights of translation, reprinting, re-use of illustrations, recitation, broadcasting, reproduction on microfilms or in any other way, and storage in data banks. Duplication of this publication or parts thereof is permitted only under the provisions of the Copyright Law of the Publisher's location, in its current version, and permission for commercial use must always be obtained from Springer. Permissions for commercial use may be obtained through RightsLink at the Copyright Clearance Center. Violations are liable to prosecution under the respective Copyright Law.

The use of general descriptive names, registered names, trademarks, etc. in this publication does not imply, even in the absence of a specific statement, that such names are exempt from the relevant protective laws and regulations and therefore free for general use.

The publisher, the authors and the editors are safe to assume that the advice and information in this book are believed to be true and accurate at the date of publication. Neither the publisher nor the authors or the editors give a warranty, express or implied, with respect to the material contained herein or for any errors or ommissions that may have been made.

Printed on acid-free paper

Adis is a brand of Springer

Springer International Publishing AG Switzerland is part of Springer Science+Business Media (www.springer.com)

This book was published with the support of Daiichi Sankyo 


\section{Contents}

1 Introduction .......................... 1

1.1 Overview of the coagulation cascade........ 1

1.2 Current approaches to anticoagulation....... 3

1.3 The ideal anticoagulant ................ 5

References .......................... 6

2 Direct thrombin inhibitors $\ldots \ldots \ldots \ldots \ldots \ldots \ldots, 7$

2.1 Historical excursus: ximelagatran........... 8

2.2 Dabigatran etexilate.................. 8

2.2.1 Venous thromboembolism prevention in major orthopedic surgery ........ 11

2.2.2 Venous thromboembolism treatment .. 16

2.2.3 Stroke prevention in atrial fibrillation. . 18

2.2.4 Other directions ................. 21

References ........................... 21

3 Factor Xa inhibitors...................... 25

3.1 Rivaroxaban ..................... 25

3.1.1 Venous thromboembolism prevention following joint surgery........... 26

3.1.2 Treatment of venous thromboembolism .............. 32

3.1.3 Stroke prevention in atrial fibrillation. . 35

3.1.4 Acute coronary syndromes .......... 36

3.2 Apixaban ....................... 37

3.2.1 Venous thromboembolism prevention in major orthopedic surgery .......... 38 
vi Contents

3.2.2 Stroke prevention in atrial fibrillation ................... 44

3.2.3 Thromboprophylaxis in other clinical settings ............. 45

3.2.4 Treatment of venous thrombosis . . . . 47

3.2 .5 Acute coronary syndrome......... 50

3.3 Edoxaban.................... 50

3.3.1 Venous thromboembolism prevention in major orthopedic surgery ....... 52

3.3.2 Stroke prevention in atrial fibrillation. . 56

3.3.3 Treatment of venous thromboembolism ............... 60

3.4 Emerging factor Xa inhibitors . . . . . . . . 63

3.4.1 Betrixaban................. 63

3.4 .2 TTP889................... 64

References .......................... 65

4 Conclusions........................ 73

4.1 Future directions. . . . . . . . . . . . . . . 74

References ....................... 75 


\section{Chapter 1 \\ Introduction}

There are several disorders which carry an increased risk of thrombosis, clots that interfere with normal circulation, including: venous thromboembolism (VTE), comprising both deep vein thrombosis (DVT) and pulmonary embolism (PE), atrial fibrillation (AF), acute coronary syndromes (ACS), valve disease and endocarditis, and conditions associated with a raised risk of ischemic stroke. Due to this increased risk, a number of thromboprophylactic medications target the coagulation cascade. Effective anticoagulation can be achieved by inhibiting different coagulation factors in the coagulation cascade.

\subsection{Overview of the Coagulation Cascade}

The coagulation cascade is composed of two pathways; the intrinsic, or contact activation pathway and the extrinsic, or tissue factor pathway (Fig. 1.1). The main function of the coagulation cascade is the formation of an insoluble fibrin clot [1]. If a hemorrhage occurs due to blood vessel injury, the coagulation system facilitates hemostasis.

A series of reactions occur throughout the coagulation cascade causing the conversion of inactive enzyme precursors to their active forms; these active forms catalyze the subsequent reactions in the cascade. The coagulation cascade 


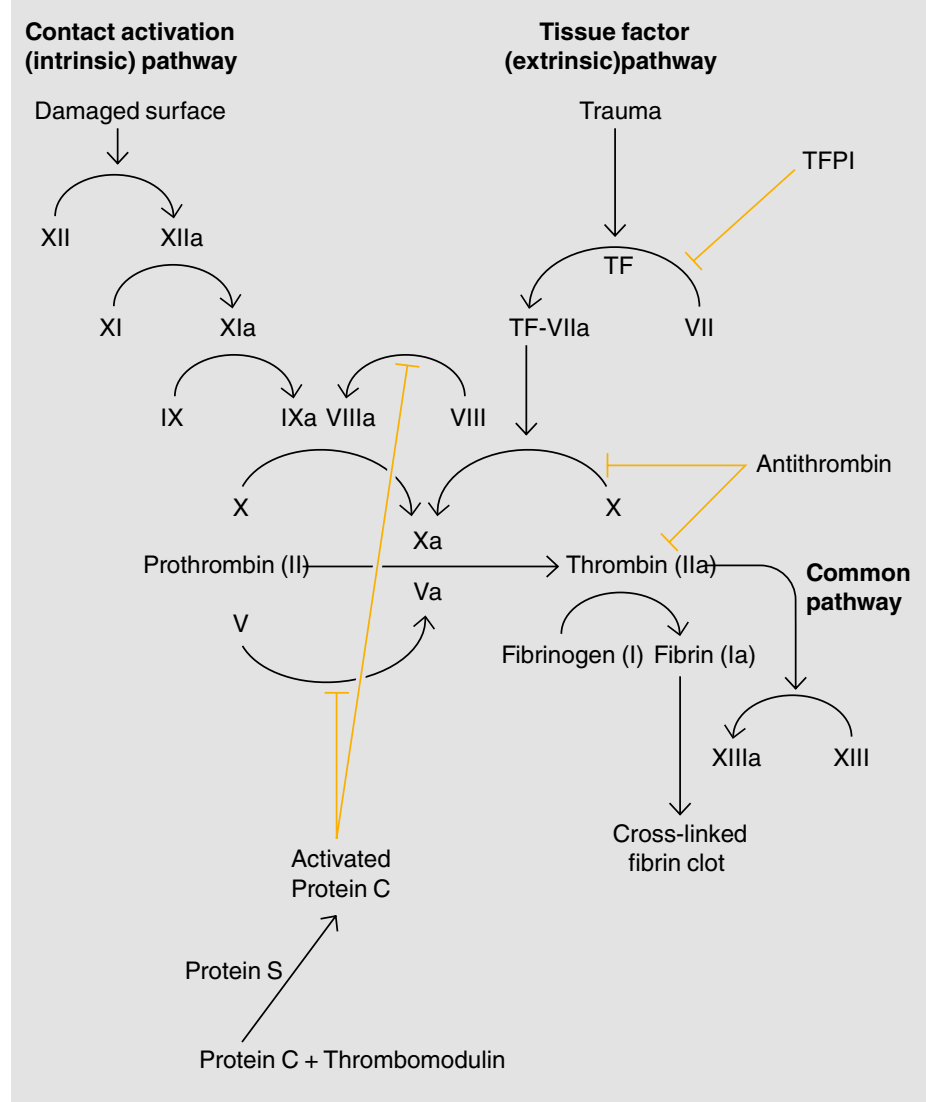

Figure I.I The coagulation cascade

prevents both excessive bleeding and excessive coagulation through a negative feedback loop, self-maintained by a regulated balance of procoagulant and anticoagulant factors.

In the extrinsic (tissue factor) pathway $[2,3]$ when the coagulation cascade is activated tissue factor (TF) is released from subendothelial tissue and comes into contact with factor VII which, in the presence of $\mathrm{Ca}^{2+}$, forms the activated complex TF-VIIa. TF-VIIa catalyzes the conversion of factor $\mathrm{X}$ to factor $\mathrm{Xa}$ which, along with activated factor $\mathrm{V}$, initiates the formation of the serum protease thrombin, formed when 
factors Va and Xa cleave prothrombin fragments 1 and 2. Thrombin then cleaves fibrinopeptides A and B from fibrinogen resulting in insoluble fibrin.

In the intrinsic (contact activation) pathway $[2,3]$ damage to the endothelial surface causes the formation of factor XIIa from factor XII, which in turn triggers formation of factor XIa from factor XI. Factor XIa catalyzes the conversion of factor IX to factor IXa (in the presence of $\mathrm{Ca}^{2+}$ ), which triggers the conversion of factor VIII to factor VIIIa. Factors IXa and VIIIa form a catalytic complex and activate factor $\mathrm{X}$. The formation of factor Xa marks the convergence of the extrinsic and intrinsic pathways into a common pathway, which is responsible for the formation of a fibrin mesh on the damaged vessel wall.

\subsection{Current Approaches to Anticoagulation}

Currently vitamin $\mathrm{K}$ antagonists (VKAs), such as warfarin, are the mainstay of anticoagulant treatment. VKAs have been the oral anticoagulant of choice for more than 50 years, with warfarin being the most commonly used VKA worldwide due to its low cost and once-daily (qd) dosing [4].

Warfarin is highly effective in the prevention of stroke and recurrent VTE, showing improved efficacy over antiplatelet therapy $[5,6]$. Indeed, warfarin has been shown to reduce the risk of VTE by $\sim 85 \%$ compared with placebo [5].Furthermore, warfarin has been found to reduce the risk of stroke by $\sim 62 \%$ (relative risk reduction, $36 \%$ [95\% confidence interval (CI) 14-52\%]), compared with aspirin [6].

Warfarin inhibits the normal production of several anticoagulation factors that are dependent upon vitamin $\mathrm{K}$ [7]. When vitamin $\mathrm{K}$ is available these anticoagulation factors are $\gamma$-carboxylated leading to the expression of their procoagulation activity. The availability of vitamin $\mathrm{K}$ depends on the normal functioning of the enzyme vitamin $\mathrm{K}$ epoxide reductase. Warfarin inhibits this enzyme leading to a lack of vitamin $\mathrm{K}$ resulting in the production of functionally impaired, partially carboxylated and decarboxylated factors with corresponding anticoagulant effects. 
Despite their efficacy, there are limitations associated with VKA treatment including: a number of drug and food interactions, individual dose-adjustment based on international normalization ratio (INR), maintenance of INR within the time in therapeutic range (TTR), and the need for constant monitoring.

The number of food and drug interactions associated with VKA use results in a substantial variability in the absorption and bioavailability of warfarin [8]. For example low-dose vitamin $\mathrm{K}$ can reverse the effects of warfarin, whereas high concentrations of vitamin $\mathrm{K}$ lead to its accumulation in the liver, which can make the patient resistant to warfarin [9]. As such, foods containing a high concentration of vitamin K (such as broccoli) can reduce the effect of warfarin [9]. Additionally, the consumption of alcohol can interact with liver enzymes which have the potential to affect the metabolism of warfarin. Furthermore, it often takes several days to reach therapeutic levels due to its long half-life (approx. $40 \mathrm{~h}$ ). Warfarin is mainly bound to albumin in the plasma and metabolized in the liver.

The effectiveness and safety of warfarin are critically dependent on maintaining the INR within a therapeutic range of 2.0-3.0. Due to the wide number of pharmacological interactions, warfarin requires regular monitoring of its anticoagulant activity and patients require individual dose adjustment.

Treatment with warfarin is associated with a number of side-effects, including increased risk of severe hemorrhagic complications, such as intracranial hemorrhage. Overanticoagulation (INR >3.0) carries a high risk of intracranial hemorrhage, which accounts for $\sim 90 \%$ of deaths from warfarin-associated hemorrhage [10]. Furthermore, the benefits of warfarin are only seen in AF patients whose minimum TTR is between 58 and $65 \%$ [11].

\subsection{The Ideal Anticoagulant}

The limitations described above complicate the use of these drugs, especially in the long term setting, and there remains a need for anticoagulants that are at least as effective but safer 
and more convenient. The development of new anticoagulants has identified a number of properties for an ideal anticoagulant'.

The ideal anticoagulant should have a quick onset of action that remains stable throughout the day. Additionally, it should target specific coagulation factors within the coagulation cascade, preferably acting independently of cofactors, with predictable anticoagulant effects, and fixed doses. Ideally, only pathological thrombosis leading to thromboembolic events would be inhibited, but a certain extension of activity of the coagulation system that maintains physiological hemostasis should be allowed [12].

From a clinical perspective, the ideal anticoagulant should have easy oral application, a wide therapeutic window, predictable pharmacodynamic and pharmacokinetic properties, and a low risk for interactions with other drugs or food, allowing for a simple dosing regimen without the need for regular monitoring. Moreover, it would have a reversible anticoagulant effect for emergency situations and the risk of hemorrhage and effects on other organs should be minimal.

A better understanding of the coagulation cascade led to identification of many targets for novel anticoagulants in the coagulation pathway. Indeed, a number of non-VKA oral anticoagulants (NOACs) have been launched or are currently in development, which have the potential to overcome the limitations associated with VKAs. With the use of NOACs, such as direct oral thrombin inhibitors (dabigatran) or factor Xa inhibitors (apixaban, rivaroxaban, edoxaban), some of the inherent problems such as regular INR monitoring, dose adjustment, and food and drug interactions, will be removed.

OpenAccess This chapter is distributed under the terms of the Creative Commons Attribution Noncommercial License, which permits any noncommercial use, distribution, and reproduction in any medium, provided the original author(s) and source are credited. 


\section{References}

1. Mackman N. Triggers, targets and treatments for thrombosis. Nature. 2008;451:914-8.

2. Mann KG, Nesheim ME, Church WR, et al. Surface-dependent reactions of the vitamin $\mathrm{K}$ dependent enzyme complexes. Blood. 1990;76:1-16.

3. De Caterina R, Husted S, Wallentin L, et al. General mechanisms of coagulation and targets of anticoagulants (Section I): Position Paper of the ESC Working Group on Thrombosis - Task Force on Anticoagulants in Heart Disease. Thromb Haemost. 2013; 109:569-79.

4. Bauersachs R. Edoxaban: a new oral direct factor Xa inhibitor for the prevention and treatment of thromboembolic disorders. Clin Invest. 2014;4:619-39.

5. Hart RG, Pearce LA, Aguilar MI. Meta-analysis: antithrombotic therapy to prevent stroke in patients who have nonvalvular atrial fibrillation. Ann Intern Med. 2007;146:857-67.

6. Hart RG, Benavente O, McBride R, Pearce LA. Antithrombotic therapy to prevent stroke in patients with atrial fibrillation: a meta-analysis. Ann Intern Med. 1999;131:492-501.

7. Malhotra OP, Nesheim ME, Mann KG. The kinetics of activation of normal and gamma carboxy glutamic acid deficient prothrombins. J Biol Chem. 1985;260:279-87.

8. Eriksson BI, Quinlan DJ, Eikelboom JW. Novel oral factor Xa and thrombin inhibitors in the management of thromboembolism. Annu Rev Med. 2011;62:41-57.

9. Holbrook AM, Pereira JA, Labiris R, et al. Systematic overview of warfarin and its drug and food interaction. Arch Intern Med. 2005;165:1095-106.

10. Fang MC, Go AS, Chang Y, et al. Death and disability from warfarin-associated intracranial and extracranial hemorrhages. Am J Med. 2007;120:700-5.

11. Connolly SJ, Pogue J, Eikelboom J, et al.; ACTIVE W Investigators. Benefit of oral anticoagulant over antiplatelet therapy in atrial fibrillation depends on the quality of international normalized ratio control achieved by centers and countries as measured by time in therapeutic range. Circulation. 2008;118:2029-37.

12. Furie B, Furie BC. Mechanisms of thrombus formation. N Engl J Med. 2008;359:938-49. 


\section{Chapter 2 \\ Direct Thrombin Inhibitors}

Anticoagulation can be achieved by inhibition of the various coagulation factors. Non-VKA oral anticoagulant (NOAC) development has focused on the synthesis of selective inhibitors of coagulation factors, preferably acting independently of cofactors. The NOACs act on a number of targets in the coagulation cascade, but two of its key factors, Xa and IIa (thrombin), are the major therapeutic targets. As they are involved in the final steps of the coagulation cascade, their inhibition allows blocking of both intrinsic and extrinsic coagulation pathways.

As the serine protease thrombin is the final mediator in the coagulation cascade that leads to the production of fibrin, is the main protein component of blood clots [1], and is also a potent activator of platelets, it has been a popular target for the development of novel anticoagulants [2]. Several direct thrombin inhibitors (DTIs) have been approved for clinical use in the prevention of thrombosis, for example desirudin. However, those agents that still require parenteral administration are not suitable for, ichronic use, and the need for development of efficient, safe, convenient, and predictable oral anticoagulants led to development of oral agents. 


\subsection{Historical Excursus: Ximelagatran}

Ximelagatran, a prodrug of melagatran, was the first oral DTI used in clinical trials from 1999. Its reproducible pharmacokinetic characteristics, rapid onset of action and relatively few interactions with food and other drugs raised hopes that it would allow effective oral anticoagulation without the need for regular INR monitoring. Advanced phase III clinical trials proved ximelagatran to be a potent anticoagulant with ability to prevent venous thromboembolism (VTE) at least as efficiently as injections of the low-molecular-weight heparin (LMWH) enoxaparin followed by administration of warfarin [3]. Ximelagatran was also found to be safe in terms of risk of hemorrhage. However, the randomized, double-blind Thrombin Inhibitor in Venous Thromboembolism Treatment (THRIVE) trial and further studies revealed that treatment with ximelagatran carried substantial risk of hepatotoxicity [4].

On the basis of health concerns ximelagatran did not receive Food and Drug Administration (FDA) approval and it was subsequently withdrawn by AstraZeneca following the EXTEND study because of fear of liver toxicity [5]. The EXTEND study was terminated due to a case of severe acute liver injury just 3 weeks after completion of the 35-day course of treatment. Even though ximelagatran has been discontinued, it is very important for practitioners to know this information since safety issues of NOACs are still a major concern.

\subsection{Dabigatran Etexilate}

Dabigatran is a potent nonpeptide DTI but it is not orally active and so its physicochemical characteristics were modified to produce a prodrug, dabigatran etexilate (Fig. 2.1). This differs from dabigatran by an ethyl group at the carboxylic acid and a hexyloxycarbonyl side chain at the amidine, and it has strong and long-lasting anticoagulant effects after oral 


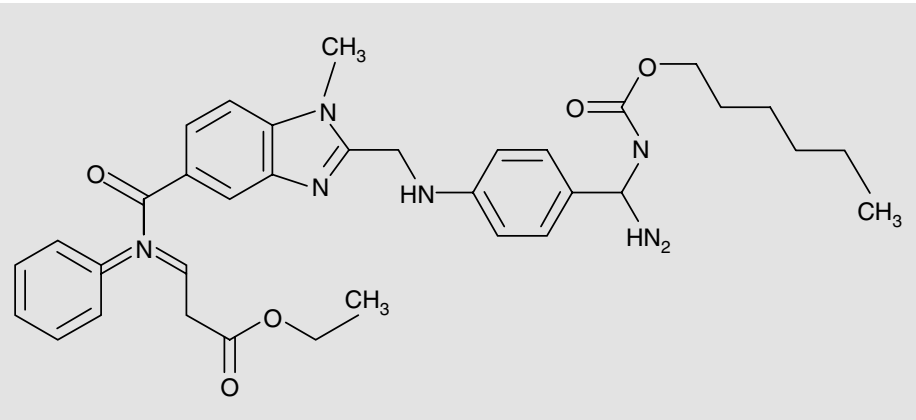

FiguRE 2.I Dabigatran etexilate

administration [6]. Dabigatran etexilate possesses a number of qualities that make it an attractive anticoagulant. It has rapid absorption (onset of action within $2 \mathrm{~h}$ ) and its half-life is approximately $8 \mathrm{~h}$ after single-dose administration and up to 14-17 h after multiple doses (Table 2.1) [7].

Dabigatran etexilate is a double prodrug that is converted by esterases into its active metabolite, dabigatran, once it has been absorbed from the gastrointestinal tract. As bioconversion of dabigatran etexilate to dabigatran begins in the gut, the drug enters the portal vein as a combination of prodrug and active compound.

The cytochrome $\mathrm{P} 450$ system plays no part in the metabolism of dabigatran etexilate; therefore, the risk of drug interactions is low. Because the bioavailability of dabigatran etexilate is only $6.5 \%$, relatively high doses of the drug must be given to ensure that adequate plasma concentrations are achieved [8]. The absorption of dabigatran etexilate in the stomach and small intestine is dependent on an acid environment. To promote such a microenvironment, dabigatran etexilate is provided in tartaric acid-containing capsules. Absorption is reduced by $20-25 \%$ if patients are concurrently on proton pump inhibitors [14]. Once it reaches the liver, bioconversion of the prodrug is completed, and approximately $20 \%$ is conjugated and excreted via the biliary system. Approximately $80 \%$ of circulated dabigatran is 


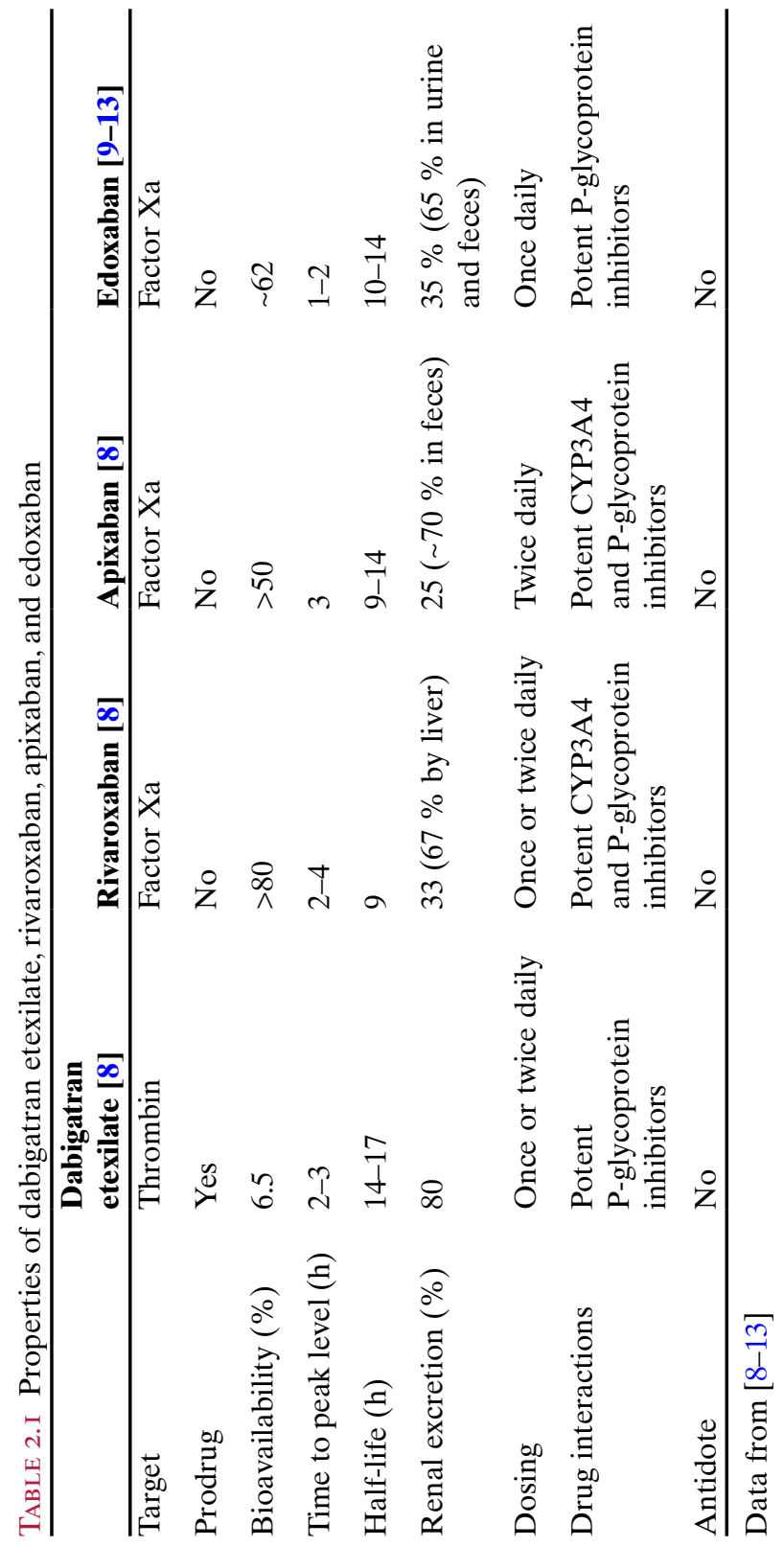


excreted unchanged via the kidneys. Consequently, plasma concentrations increase in patients with renal insufficiency. It is contraindicated in patients with severe renal failure.

It is noteworthy that dabigatran etexilate has no known interactions with food, as well as having a low potential for drug interactions [2]. Accumulated evidence from completed and ongoing trials confirms the hepatic safety of the drug [15].

Dabigatran etexilate has been evaluated in a number of phase II and phase III studies in several disorders (Table 2.2).

\subsubsection{Venous Thromboembolism Prevention in Major Orthopedic Surgery}

Clinical evaluation of dabigatran etexilate started in the setting of major joint surgery. In the multicenter, open-label, phase II BISTRO I trial [16], 314 patients undergoing total hip replacement (THR) were assigned to receive different doses of dabigatran etexilate $(12.5,25,50,100,150,200$, or $300 \mathrm{mg}$ twice daily (bid), or 150 or $300 \mathrm{mg} \mathrm{qd}$ ) administered 4-8 h after surgery for 6-10 days. No major hemorrhages were observed in any group. However, non-major multiplesite hemorrhage was observed in two patients with reduced renal clearance treated with the highest dose (300 mg bid). The overall incidence of deep vein thrombosis (DVT) was $12.4 \%$, without a consistent relationship between incidence and dose. The lowest dose (12.5 mg bid) showed a high rate of proximal DVT $(12.5 \%)$.

In the subsequent phase II BISTRO II trial [17] the 1973 patients undergoing THR or total knee replacement (TKR) were randomized to 6-10 days of dabigatran etexilate (50, 150 , or $225 \mathrm{mg}$ bid, or $300 \mathrm{mg}$ qd) starting 1-4 h after surgery, or enoxaparin ( $40 \mathrm{mg} \mathrm{qd}$ ) starting $12 \mathrm{~h}$ prior to surgery. VTE occurred in 28.5, 17.4, 13.1, 16.6, and $24 \%$ of patients assigned to dabigatran etexilate $50,150,225 \mathrm{mg}$ bid, $300 \mathrm{mg} \mathrm{qd}$, and enoxaparin, respectively. Compared with enoxaparin, VTE was significantly lower in patients receiving 150 or $225 \mathrm{mg}$ bid or $300 \mathrm{mg} \mathrm{qd}$, and major hemorrhage was significantly lower 
TABLE 2.2 Clinical development program for dabigatran etexilate

\begin{tabular}{lll}
\hline Clinical condition & Trial & Comparator (n) \\
\hline $\begin{array}{l}\text { VTE prevention in } \\
\text { major joint surgery }\end{array}$ & Phase II & \\
& BISTRO I [16] & No comparator (314) \\
& BISTRO II [17] & Enoxaparin (1973) \\
& Phase III & \\
& RE-MODEL [18] & Enoxaparin (2076) \\
& RE-NOVATE [19] & Enoxaparin (3494) \\
& RE-MOBILZE [20] & Enoxaparin (1896) \\
& RE-NOVATE II [21] Enoxaparin (1920)
\end{tabular}

VTE treatment Phase III

$$
\begin{array}{ll}
\text { RE-COVER [22] } & \begin{array}{l}
\text { Parenteral } \\
\text { anticoagulant/warfarin } \\
(2564)
\end{array} \\
\text { RE-COVER II [23] } & \begin{array}{l}
\text { Parenteral } \\
\text { anticoagulant/warfarin } \\
(2589)
\end{array} \\
\text { RE-SONATE [24] } & \begin{array}{l}
\text { Placebo (1353) } \\
\text { RE-MEDY [24] }
\end{array} \\
\text { Warfarin (2866) }
\end{array}
$$

Stroke prevention Phase II

in atrial fibrillation

PETRO [25] Aspirin or warfarin (502)

Phase III

$$
\begin{array}{ll}
\text { RE-LY [26] } & \text { Warfarin }(18,000) \\
\text { RELY-ABLE [27] } & \text { Placebo }(5851)
\end{array}
$$

Acute coronary RE-DEEM [28] Placebo (1878)

syndrome

Percutaneous D-fine [29] Heparin (50)

coronary

intervention

Data from [16-29]

$V T E$ venous thromboembolism 
with $50 \mathrm{mg}$ bid but elevated with higher doses, nearly achieving statistical significance with the $300 \mathrm{mg}$ qd dose $(P=0.051)$. Together, the BISTRO I and BISTRO II trials showed that dabigatran etexilate might be an effective and safe anticoagulant and served as a basis for dose justification in phase III trials.

The clinical utility of dabigatran etexilate for the prevention of VTE in patients after major joint surgery was confirmed in three large randomized, double-blind, multicenter trials (Table 2.3) [18-21]. The RE-MODEL trial [18] compared dabigatran etexilate $(150 \mathrm{mg}$ or $220 \mathrm{mg} \mathrm{qd}$, starting with a half-dose $1-4 \mathrm{~h}$ after TKR) and enoxaparin (40 mg qd starting the evening before surgery in 2076 patients). The treatment continued for 6-10 days and patients were followed up for 3 months. The primary efficacy outcome of a composite of total VTE (venographic or symptomatic) and mortality during treatment occurred in $37.7 \%$ of patients in the enoxaparin group, $36.4 \%$ of the dabigatran etexilate $220 \mathrm{mg}$ group and $40.5 \%$ of the $150 \mathrm{mg}$ dabigatran etexilate group. Both dabigatran etexilate doses proved to be noninferior to enoxaparin. The incidence of major hemorrhage also did not differ significantly across the three groups (1.3\%, $1.5 \%$, and $1.3 \%$, respectively).

A similar design was used in the RE-NOVATE trial [19] to test potential non-inferiority of dabigatran etexilate for VTE prophylaxis in 3494 patients undergoing THR, except that the treatment was continued for 28-35 days. The primary efficacy outcome, a composite of total VTE and all-cause mortality during treatment, occurred in $6.7 \%$ of individuals in the enoxaparin group, $6.0 \%$ of patients in the dabigatran etexilate $220 \mathrm{mg}$ qd group, and $8.6 \%$ of patients in the $150 \mathrm{mg} \mathrm{qd}$ group; that is, both the dabigatran etexilate doses were noninferior to enoxaparin. There was no significant difference in major hemorrhage rates with either dose of dabigatran etexilate compared with enoxaparin. In the phase III RE-NOVATE II trial, the efficacy and safety of oral dabigatran versus subcutaneous enoxaparin was compared for extended thromboprophylaxis in patients undergoing total hip arthroplasty. 
14 Chapter 2. Direct Thrombin Inhibitors

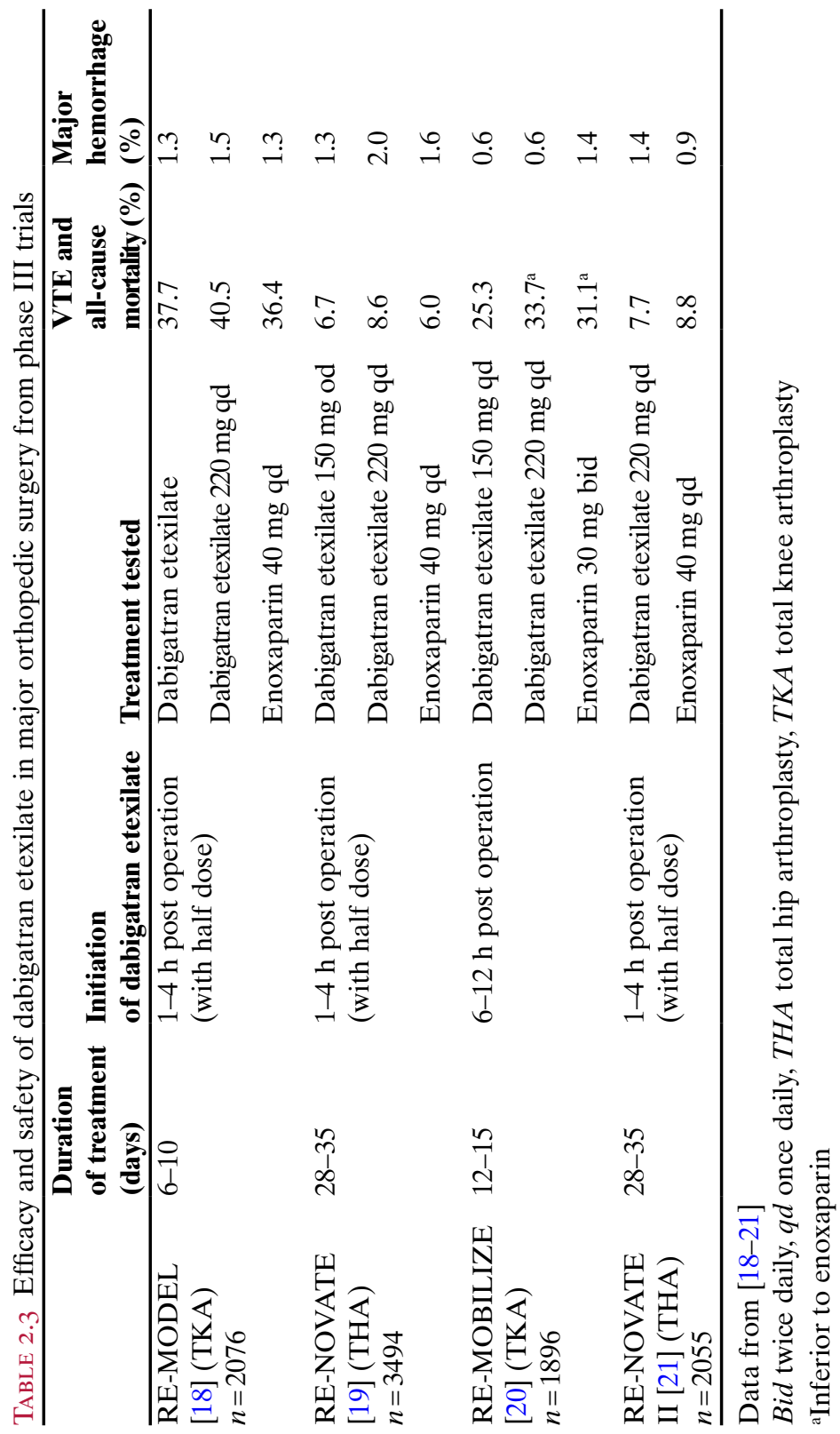


A total of 2055 patients were randomized. The primary efficacy outcome was a composite of total VTE and death from all causes. The main secondary composite outcome was major VTE plus VTE-related death. The main safety endpoint was major bleeding. The primary efficacy outcome occurred in $7.7 \%$ of the dabigatran group versus $8.8 \%$ of the enoxaparin group $(P<0.0001$ for the pre-specified non-inferiority margin). Major VTE plus VTE-related death occurred in $2.2 \%$ of the dabigatran group versus $4.2 \%$ of the enoxaparin group. Major bleeding events did not differ between the two arms [21].

No significant differences in the incidences of liver enzyme elevation and acute coronary events were observed during treatment or follow-up in the RE-MODEL or the RE-NOVATE I and II trials.

The successful record of dabigatran etexilate in preceding clinical trials was partly compromised in the double-blind, centrally randomized RE-MOBILIZE trial [20], in which the North American recommended dose for VTE prophylaxis was used for the enoxaparin comparator (i.e., $30 \mathrm{mg}$ bid rather than $40 \mathrm{mg} q d)$. Dabigatran etexilate 220 or $150 \mathrm{mg}$ qd was compared with enoxaparin $30 \mathrm{mg}$ bid after knee arthroplasty surgery. Among 1896 patients, dabigatran etexilate at both doses showed inferior efficacy to enoxaparin, with VTE rates of $31 \%$ for $220 \mathrm{mg}$ qd ( $P=0.02$ versus enoxaparin), $34 \%$ for $150 \mathrm{mg}$ qd $(P<0.001$ versus enoxaparin $)$, and $25 \%$ for enoxaparin. Major hemorrhage was uncommon in all groups: $0.6 \%$ for dabigatran $220 \mathrm{mg} \mathrm{qd}, 0.6 \%$ for dabigatran $150 \mathrm{mg} \mathrm{qd}$, and $1.4 \%$ for enoxaparin (no significant differences). Serious adverse events occurred in $6.9 \%$ of dabigatran $220 \mathrm{mg}$ qd patients, $6.5 \%$ of dabigatran $150 \mathrm{mg} \mathrm{qd}$ patients, and $5.2 \%$ of enoxaparin patients.

An interesting clinical difference between European and North American prophylactic dosing regimens for antithrombotic drugs for perioperative orthopedic patients is that, historically, European dosing regimens administered these drugs before surgery, whereas in North America dosing began postoperatively, sometimes at a higher total daily 
dosage [30]. Because dabigatran was first investigated in European joint arthroplasty patients, the LMWH control therapy, enoxaparin, was initiated the evening before the day of surgery at the standard dosage of $40 \mathrm{mg}$ qd in the phase II studies.

In March 2008, the European Commission granted marketing authorization for dabigatran etexilate for the prevention of VTE in adults who have undergone THR or TKR. The drug was launched in the UK in April 2008.

A number of observational cohort studies aimed to further optimize clinical management with dabigatran in VTE following joint surgery by selecting specific patient groups and treatment regimens. A recently completed study (ClinicalTrials.gov Identifier NCT00846807) [31] investigated the safety and efficacy of dabigatran $220 \mathrm{mg}$ in patients with an increased risk of bleeding or VTE and an ongoing study (ClinicalTrials. gov Identifier NCT00847301) [32] evaluating the safety and efficacy of dabigatran $150 \mathrm{mg}$ in patients with renal impairment has been recently completed and its results are awaited.

\subsubsection{Venous Thromboembolism Treatment}

The promising efficacy results for dabigatran in the prevention of thromboembolic disorders following major joint surgery prompted the developers to test the drug's utility in VTE treatment (Table 2.2) [16-27].

The RE-COVER study was a randomized, double-blind, non-inferiority trial involving 1274 patients with acute VTE who were initially given parenteral anticoagulation therapy for a median of 9 days [22]. The RE-COVER population was assigned to dabigatran, administered at a dose of $150 \mathrm{mg}$ bid, or dose-adjusted warfarin. The primary outcome was the 6-month incidence of recurrent VTE and related deaths. Safety endpoints included bleeding events, acute coronary syndrome (ACS) events, other adverse events, and results of liver-function tests. The RE-COVER investigators concluded that for the treatment of acute VTE, a fixed dose of 
TABLE 2.4 Efficacy and safety of dabigatran etexilate in phase III VTE trials

\begin{tabular}{|c|c|c|c|c|c|}
\hline & & Dabigatr: & & Comparat & \\
\hline & $\begin{array}{l}\text { Duration } \\
\text { of treatment } \\
\text { (months) }\end{array}$ & $\begin{array}{l}\text { VTE and } \\
\text { all-cause } \\
\text { mortality } \\
n / N(\%)\end{array}$ & $\begin{array}{l}\text { Major } \\
\text { hemorrhage } \\
n / N(\%)\end{array}$ & $\begin{array}{l}\text { VTE and } \\
\text { all-cause } \\
\text { mortality } \\
n / N(\%)\end{array}$ & $\begin{array}{l}\text { Major } \\
\text { hemorrhage } \\
n / N(\%)\end{array}$ \\
\hline $\begin{array}{l}\text { RE-COVER } \\
{[22]} \\
n=2564\end{array}$ & 6 & $\begin{array}{l}30 / 1274 \\
(2.4)\end{array}$ & $\begin{array}{l}\text { 20/1274 } \\
(1.6)\end{array}$ & $\begin{array}{l}27 / 1265 \\
(2.1)\end{array}$ & $\begin{array}{l}24 / 1265 \\
(1.9)\end{array}$ \\
\hline $\begin{array}{l}\text { RE-COVER } \\
\text { II }[23] \\
n=2589\end{array}$ & 6 & $\begin{array}{l}30 / 1279 \\
(2.3)\end{array}$ & $\begin{array}{l}15 / 1279 \\
(1.2)\end{array}$ & $\begin{array}{l}28 / 1289 \\
(2.2)\end{array}$ & $\begin{array}{l}22 / 1289 \\
(1.7)\end{array}$ \\
\hline $\begin{array}{l}\text { RE-MEDY } \\
{[24]} \\
n=2866\end{array}$ & $6-36$ & $\begin{array}{l}26 / 1430 \\
(1.8)\end{array}$ & $\begin{array}{l}13 / 1430 \\
(0.9)\end{array}$ & $\begin{array}{l}18 / 1426 \\
(1.3)\end{array}$ & $\begin{array}{l}25 / 1426 \\
(1.8)\end{array}$ \\
\hline $\begin{array}{l}\text { RE-SONATE } \\
{[24]} \\
n=1353\end{array}$ & $6-18$ & $\begin{array}{l}3 / 681 \\
(0.4)\end{array}$ & $\begin{array}{l}2 / 681 \\
(0.3)\end{array}$ & $\begin{array}{l}37 / 662 \\
(5.6)\end{array}$ & $0 / 0(0.0)$ \\
\hline
\end{tabular}

Data from [22-24]

$V T E$ venous thromboembolism

dabigatran is as effective as warfarin (primary outcome rate $2.4 \%$ versus $2.1 \%$, respectively; $P<0.001$ for the pre-specified non-inferiority margin) and has a safety profile that is similar to that of warfarin (Table 2.4) [22]. Based on the success of RE-COVER, RE-COVER II was initiated to confirm the low rate of recurrent VTE observed. RE-COVER II was a 6-month, double-blind, randomized trial comparing treatment with dabigatran to warfarin in 2589 VTE patients (either acute symptomatic proximal DVT or pulmonary embolism). Patients were randomized to dabigatran $150 \mathrm{mg}$ bid or dose-adjusted warfarin (INR 2.0-3.0). The primary efficacy and safety outcomes were the same as those used in RE-COVER. RE-COVER II confirmed the non-inferiority of dabigatran (primary outcome occurred in $2.3 \%$ of patients treated with dabigatran vs $2.2 \%$ of patients treated with warfarin; $P<0.001$ ) (Table 2.4). Additionally, RE-COVER II 
confirmed the superiority of dabigatran for clinically relevant non-major (CRNM) bleeding and for any bleeding [23].

In a separate phase III randomized multicenter trial, RE-SONATE, the efficacy of prolonged (additional 12 months) administration of dabigatran etexilate in 1547 patients with VTE was compared with placebo. In RE-SONATE, extended treatment with dabigatran was associated with a $92 \%$ relative risk reduction for recurrent VTE and a low risk for major bleeding [24]. Additionally, the RE-MEDY trial evaluated the comparative safety and efficacy of dabigatran etexilate and warfarin for the long-term treatment and secondary prevention of symptomatic VTE in 2866 patients already successfully treated with a standard anticoagulant approach for 3-6 months for confirmed acute symptomatic VTE. In RE-MEDY, dabigatran demonstrated non-inferiority to warfarin for the outcome of recurrent VTE (primary outcome rate $1.8 \%$ vs $1.3 \%$ respectively; $P=0.01$ for non-inferiority), with fewer bleeds (19.4\% vs $26.2 \%$, respectively; $P<0.001)$, but there were more ACS events in the dabigatran group than in those taking warfarin $(0.9 \%$ vs $0.2 \% ; P=0.02$ ) (Table 2.4) [24].

\subsubsection{Stroke Prevention in Atrial Fibrillation}

The clinical safety of dabigatran etexilate (with or without aspirin) in patients with atrial fibrillation (AF) was first assessed in the phase II dose-range Prevention of Embolic and ThROmbotic Events in Patients with Persistent Atrial Fibrillation (PETRO) trial [25]. In this trial, 502 patients with AF were randomized to receive dabigatran etexilate 50, 150, or $300 \mathrm{mg}$ bid alone or combined with $81 \mathrm{mg}$ or $325 \mathrm{mg}$ of aspirin or warfarin qd for 12 weeks. Major hemorrhage was limited to the group treated with $300 \mathrm{mg}$ dabigatran plus aspirin (4 of 64), and the incidence was significant versus $300 \mathrm{mg}$ dabigatran alone (0 of 105, $P<0.02$ ). Total hemorrhage events were more frequent in the $300 \mathrm{mg}(23 \%)$ and $150 \mathrm{mg}$ (18\%) dabigatran groups compared with the $50 \mathrm{mg}$ 
groups ( $7 \% ; P=0.0002$ and $P=0.01$, respectively). The study demonstrated that major hemorrhages were limited to patients treated with dabigatran $300 \mathrm{mg}$ plus aspirin, and thromboembolic episodes were limited to the $50 \mathrm{mg}$ dabigatran groups. On the basis of the PETRO study, 150 and $220 \mathrm{mg}$ doses were chosen for further development in phase III studies of stroke prevention in AF.

The Randomized Evaluation of Long term anticoagulant therapy (RE-LY) with dabigatran etexilate trial compared the efficacy and safety of two doses of dabigatran etexilate with warfarin in over 18,000 patients with AF with an average age of 71 years. The primary outcome measure was the incidence of stroke (including hemorrhagic) or systemic embolism at the median 2-year follow-up period. Treatment with the higher, $150 \mathrm{mg}$ bid dose significantly reduced the rate of stroke and systemic embolism (with a relative risk of $0.66, P<0.001$; the rate of hemorrhagic stroke was $0.38 \%$ per year in the warfarin group versus $0.10 \%$ per year with dabigatran, $P<0.001$ ), with a similar overall risk to warfarin for major bleeding [26]. The lower, $110 \mathrm{mg}$ bid dose resulted in a similar risk for stroke as warfarin but with a significantly reduced major bleeding event rate $(20 \%$ relative risk reduction, $3.36 \%$ per year in the warfarin group versus $2.71 \%$ per year with dabigatran, $P=0.003$ ). The rate of hemorrhagic stroke was $0.38 \%$ per year in the warfarin group, as compared with $0.12 \%$ per year with $110 \mathrm{mg}$ dabigatran $(P<0.001)$ and $0.10 \%$ per year with $150 \mathrm{mg}$ of dabigatran $(P<0.001)$. Annual mortality rate was $4.13 \%$ in the warfarin group, $3.75 \%$ with $110 \mathrm{mg}$ of dabigatran and $3.64 \%$ with $150 \mathrm{mg}$ of dabigatran (borderline significance, $P=0.051$ ) [26] (Fig. 2.2). The longterm extension study, RELY-ABLE, investigated the safety of prolonged treatment with dabigatran etexilate; 5851 patients who completed dabigatran treatment in the RE-LY study were enrolled into RELY-ABLE to continue with the two effective doses of dabigatran (110 and $150 \mathrm{mg}$ ). Primary outcomes for RELY-ABLE were the same as those for RE-LY. For both doses studied, the rates of major ischemic, 


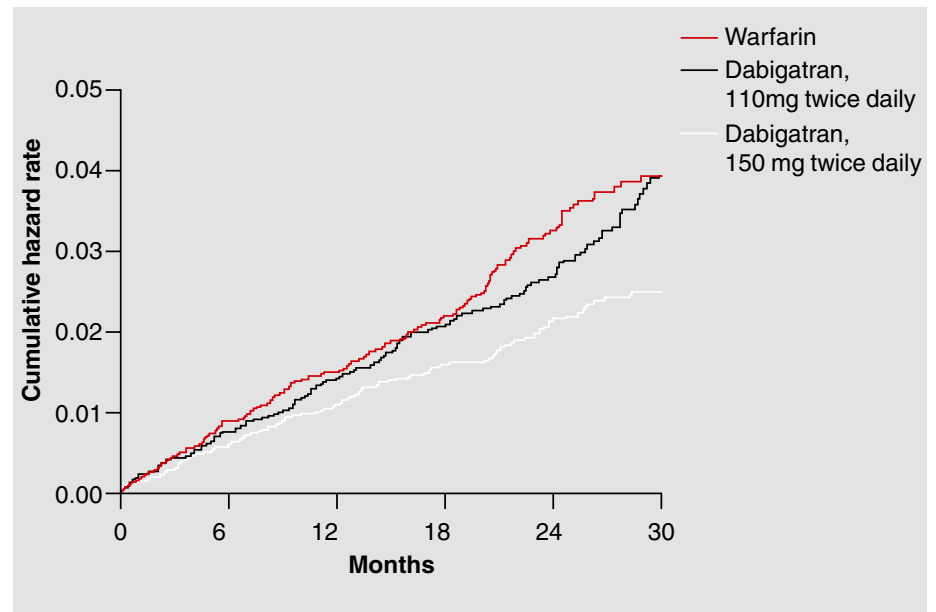

FIGURE 2.2 Cumulative hazard rates for the primary outcome of stroke or systemic embolism, according to treatment group (Reproduced with permission from Connolly et al. [26])

hemorrhagic and fatal outcomes were consistent with those seen in RE-LY, demonstrating the safety of both doses in long-term treatment. RELY-ABLE did not show any significant differences between the two doses in the rate of stroke (1.46\%/year for $150 \mathrm{mg}$ vs $1.60 \%$ /year for $110 \mathrm{mg}$ ) or mortality (3.02\%/year for $150 \mathrm{mg}$ vs $3.10 \% / y e a r$ for $110 \mathrm{mg}$ ), however there was a higher rate of bleeding in the $150 \mathrm{mg}$ patient group (3.74\%/year vs $2.99 \% /$ year) [27].

In view of the results of the RE-LY trial, dabigatran has been included in the latest European guidelines for management of AF as an alternative to VKAs for primary or secondary prevention of stroke in patients with AF. In October 2010 the United States (US) FDA approved the $150 \mathrm{mg}$ bid dosage, which should be reduced to $75 \mathrm{mg}$ bid in selected cases (e.g., creatinine clearance 15-30 mL/min). Dabigatran is licensed by the European Medicines Agency (EMA) at two dosages (110 mg and $150 \mathrm{mg}$ bid), depending on the balance between thromboembolic and bleeding risk factors. 


\subsubsection{Other Directions}

The potential application of DTIs is not limited to conditions related to venous thrombosis, and dabigatran etexilate has also been tested in phase II trials in clinical settings of arterial thrombosis. In the phase II, randomized, open-label D-fine study of dabigatran etexilate in elective percutaneous coronary intervention (PCI) two doses of dabigatran etexilate (110 $\mathrm{mg}$ and $150 \mathrm{mg}$ bid) were compared with heparin (both in addition to a standard dual antiplatelet regimen) in 50 patients undergoing elective PCI. The results of this study suggested that treatment with dabigatran (both 110 and $150 \mathrm{mg}$ ) may not provide sufficient anticoagulation during PCI [29]. RE-DEEM (Dose-Finding Study for Dabigatran Etexilate in Patients With Acute Coronary Syndrome), a larger $(n=1878)$ placebo-controlled trial, evaluated the safety and potential efficacy of four different dabigatran doses administered twice daily for 6 months in addition to dual antiplatelet treatment in patients with ACS at high risk of cardiovascular complications [28]. In the RE-DEEM study dabigatran, in addition to dual antiplatelet therapy, was associated with a dose-dependent increase in bleeding events compared with placebo and significantly reduced coagulation activity in patients with a recent myocardial infarction [28].

OpenAccess This chapter is distributed under the terms of the Creative Commons Attribution Noncommercial License, which permits any noncommercial use, distribution, and reproduction in any medium, provided the original author(s) and source are credited.

\section{References}

1. Mackman N. Triggers, targets and treatments for thrombosis. Nature. 2008;451:914-8.

2. Di Nisio M, Middeldorp S, Büller HR. Direct thrombin inhibitors. N Engl J Med. 2005;353:1028-40.

3. Wallentin L, Wilcox RG, Weaver WD, et al.; Esteem Investigators. Oral ximelagatran for secondary prophylaxis after myocardial infarction: the ESTEEM randomised controlled trial. Lancet. 2003;362:789-97. 
4. Fiessinger JN, Huisman MV, Davidson BL, et al.; THRIVE Treatment Study Investigators. Ximelagatran vs low-molecularweight heparin and warfarin for the treatment of deep vein thrombosis: a randomized trial. JAMA. 2005;293:681-9.

5. Agnelli G, Eriksson BI, Cohen AT, et al; on behalf of the EXTEND Study Group. Safety assessment of new antithrombotic agents: Lessons from the EXTEND study on ximelagatran. Thromb Res. 2009;123:488-97.

6. Wienen W, Stassen JM, Priepke H, et al. Effects of the direct thrombin inhibitor dabigatran and its orally active prodrug, dabigatran etexilate, on thrombus formation and bleeding time in rats. Thromb Haemost. 2007;98:333-8.

7. Stangier J, Stahle H, Rathgen K, Fuhr R. Pharmacokinetics and pharmacodynamics of the direct oral thrombin inhibitor dabigatran in healthy elderly subjects. Clin Pharmacokinet. 2008;47: 47-59.

8. Eriksson BI, Quinlan DJ, Weitz JL. Comparative pharmacodynamics and pharmacokinetics of oral direct thrombin and factor xa inhibitors in development. Clin Pharmacokinet. 2009;48:1-22.

9. Ruff CT, Giugliano RP. New antithrombotic strategies. Hot Top Cardiol. 2009;18:1-32.

10. Ogata K, Mendell-Harary J, Tachibana M, et al. Clinical safety, tolerability, pharmacokinetics, and pharmacodynamics of the novel factor Xa inhibitor edoxaban in healthy volunteers. J Clin Pharmacol. 2010;50:743-53.

11. Ansell J. Will the new target-specific oral anticoagulants improve the treatment of venous thromboembolism? Thromb Haemost. 2012;107:1009-11.

12. Matsushima N, Lee F, Sato T, Weiss D, Mendell J. Bioavailability and safety of the factor Xa inhibitor edoxaban and the effects of quinidine in healthy subjects. Clin Pharmacol Drug Dev. 2013;2:358-66.

13. Gonzalez-Quesada CJ, Giugliano RP. Comparison of the phase III clinical trial designs of novel oral anticoagulants versus warfarin for the treatment of nonvalvular atrial fibrillation: implications for clinical practice. Am J Cardiovasc Drugs. 2014; 14:111-27.

14. Stangier J, Rathgen K, Stahle H, et al. The pharmacokinetics, pharmacodynamics and tolerability of dabigatran etexilate, a new oral direct thrombin inhibitor, in healthy male subjects. Br J Clin Pharmacol. 2007;64:292-303. 
15. Gross PL, Weitz JI. New anticoagulants for treatment of venous thromboembolism. Arterioscler Thromb Vasc Biol. 2008;28: $380-6$.

16. Eriksson BI, Dahl OE, Ahnfelt L, et al. Dose escalating safety study of a new oral direct thrombin inhibitor, dabigatran etexilate, in patients undergoing total hip replacement: BISTRO I. J Thromb Haemost. 2004;2:1573-80.

17. Eriksson BI, Dahl OE, Büller HR, et al; BISTRO II Study Group. A new oral direct thrombin inhibitor, dabigatran etexilate, compared with enoxaparin for prevention of thromboembolic events following total hip or knee replacement: the BISTRO II randomized trial. J Thromb Haemost. 2005;3:103-11.

18. Eriksson BI, Dahl OE, Rosencher N, et al; RE-MODEL Study Group. Oral dabigatran etexilate vs. subcutaneous enoxaparin for the prevention of venous thromboembolism after total knee replacement: the RE-MODEL randomized trial. J Thromb Haemost. 2007;5:2178-85.

19. Eriksson BI, Dahl OE, Rosencher N, et al.; RE-NOVATE Study Group. Dabigatran etexilate versus enoxaparin for prevention of venous thromboembolism after total hip replacement: a randomised, double-blind, non-inferiority trial. Lancet. 2007;370: 949-56.

20. RE-MOBILIZE Writing Committee; Ginsberg JS, Davidson Bl, Comp PC, et al. Oral thrombin inhibitor dabigatran etexilate vs North American enoxaparin regimen for prevention of venous thromboembolism after knee arthroplasty surgery. J Arthroplasty. 2009;24:1-9.

21. Eriksson BI, Dahl OE, Huo MH, et al; RE-NOVATE II Study Group. Oral dabigatran versus enoxaparin for thromboprophylaxis after primary total hip arthroplasty (RE-NOVATE II*). A randomised, double-blind, non-inferiority trial. Thromb Haemost. 2011;105:721-9.

22. Schulman S, Kearon C, Kakkar AK, et al; RE-COVER Study Group. Dabigatran versus warfarin in the treatment of acute venous thromboembolism. N Engl J Med. 2009;361:2342-52.

23. Schulman S, Kakkar AK, Goldhaber SZ, et al. Treatment of acute venous thromboembolism with dabigatran or warfarin and pooled analysis. Circulation. 2014;129:764-72.

24. Schulman S, Kearon C, Kakkar AK, et al. Extended use of dabigatran, warfarin, or placebo in venous thromboembolism. $\mathrm{N}$ Engl J Med. 2013;368:709-18. 
25. Ezekowitz MD, Reilly PA, Nehmiz G, et al. Dabigatran with or without concomitant aspirin compared with warfarin alone in patients with nonvalvular atrial fibrillation (PETRO study). Am J Cardiol. 2007;100:1419-26.

26. Connolly SJ, Ezekowitz MD, Yusuf S, et al.; RE-LY Steering Committee and Investigators. Dabigatran versus warfarin in patients with atrial fibrillation. N Engl J Med. 2009;361: 1139-51.

27. Connolly SJ, Wallentin L, Ezekowitz MD, et al. The long-term multicenter observational study of dabigatran treatment in patients with atrial fibrillation (RELY-ABLE) study. Circulation. 2013;128:237-43.

28. Oldgren J, Budaj A, Granger CB, et al; RE-DEEM Investigators. Dabigatran vs. placebo in patients with acute coronary syndromes on dual antiplatelet therapy: a randomized, doubleblind, phase II trial. Eur Heart J. 2011;32:2781-9.

29. Vranckx P, Verheugt FW, de Maat MP, et al. A randomised study of dabigatran in elective percutaneous coronary intervention in stable coronary artery disease patients. EuroIntervention. 2013;8:1052-60.

30. Colwell CW, Spiro TE. Efficacy and safety of enoxaparin to prevent deep vein thrombosis after hip arthroplasty. Clin Orthop Relat Res. 1995;319:215.

31. Boehringer Ingelheim. Pradaxa (Dabigatran Etexilate) 220 $\mathrm{mg} / \mathrm{q}$.d. in the general population after hip or knee replacement surgery [clinicalTrials.gov Identifier NCT00846807]. US National Institutes of Health, clinicaltrials.gov. Available at: www.clinicaltrials.gov. Accessed 21 Nov 2014.

32. Boehringer Ingelheim. Pradaxa (Dabigatran Etexilate) 150 mg/q.d. in patients with moderate renal impairment after hip or knee replacement surgery [clinicalTrials.gov Identifier NCT00847301]. US National Institutes of Health, clinicaltrials. gov. Available at: www.clinicaltrials.gov. Accessed 21 Nov 2014. 


\section{Chapter 3 \\ Factor Xa Inhibitors}

Factor Xa represents an attractive target for antithrombotic drugs as blockade of factor Xa permits inhibition of both the extrinsic and intrinsic coagulation pathways. Several factor $\mathrm{Xa}$ inhibitors, such as rivaroxaban, apixaban and edoxaban, have been approved for certain conditions, and are also in clinical development for other indications.

\subsection{Rivaroxaban}

Rivaroxaban (Fig. 3.1) is a novel factor Xa inhibitor that exhibits predictable pharmacokinetics, with high oral bioavailability, rapid onset of action (achieves maximum plasma concentration in 1.5-2.0 h), and no known food interactions [1] (see Table 2.1). The drug has a dual mode of elimination: two-thirds of it is metabolized by the liver (mostly via CYP3A4 and CYP2J2), with no major or active circulating metabolites identified, and one-third is excreted unchanged by the kidneys. Elimination of rivaroxaban from plasma occurs with a terminal half-life of 5-9 h in young individuals, and with a terminal half-life of $12-13 \mathrm{~h}$ in subjects aged $>75$ years [2]. Available data indicate that body weight, age, and gender do not have a clinically relevant effect on the 


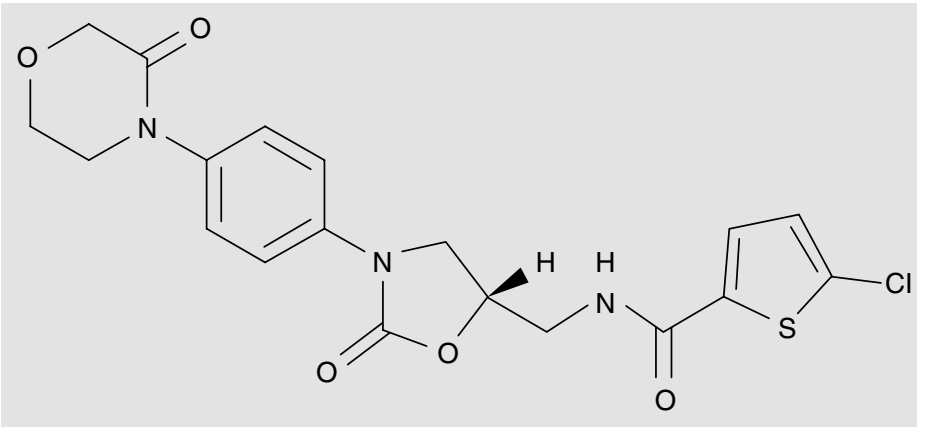

FIGURE 3.I Rivaroxaban

pharmacokinetics and pharmacodynamics of rivaroxaban, and it thus can be administered in fixed doses without coagulation monitoring. Rivaroxaban has minimal drug interactions (eg, with naproxen, acetylsalicylic acid, clopidogrel, or digoxin) [1] and its predictable pharmacokinetics and pharmacodynamics allow use of rivaroxaban without regular laboratory monitoring. Although no specific antidote is known for rivaroxaban, preclinical data suggested that recombinant factor VIIa and activated prothrombin complex concentrate may reverse the effects of high-dose rivaroxaban [3-5]. The clinical development programs for rivaroxaban are outlined in Table 3.1 [6-23].

\subsubsection{Venous Thromboembolism Prevention following Joint Surgery}

Four completed phase II efficacy and safety studies of rivaroxaban for the prevention of venous thromboembolism (VTE) in patients undergoing elective total hip replacement (THR) and total knee replacement (TKR) $(n=2907$ patients) have demonstrated comparable efficacy and safety of rivaroxaban and conventional management with subcutaneous enoxaparin [6-9, 24]. Efficacy was assessed as a composite of 
TABLE 3.I Clinical development program from rivaroxaban

\begin{tabular}{lll}
\hline Clinical condition & Trial & Comparator (n) \\
\hline $\begin{array}{l}\text { VTE prevention } \\
\text { sollowing joint }\end{array}$ & Phase II & \\
& & \\
& ODIXa-HIP [6] & Enoxaparin (722) \\
& ODIXa-KNEE [7] & Enoxaparin (621) \\
& ODIXa-OD-HIP [8] & Enoxaparin (873) \\
& Phase III & \\
& RECORD1 [9] & Enoxaparin (3153) \\
& RECORD2 [10] & $\begin{array}{l}\text { Enoxaparin + placebo } \\
\text { (2509) }\end{array}$ \\
& RECORD3 [11] & Enoxaparin (2556) \\
& RECORD4 [12] & Enoxaparin (3148) \\
& Phase II & \\
& ODIXa-DVT [13] & Enoxaparin/VKA (613) \\
& EINSTEIN DVT & LMWH/VKA (543) \\
dose ranging [14] & \\
& Phase III & \\
EINSTEIN DVT & Enoxaparin/VKA \\
& {$[15]$} & (3449) \\
& EINSTEIN PE & Enoxaparin/VKA \\
& {$[16]$} & Placebo (1197) \\
& EINSTEIN-Ext & \\
& {$[17]$} &
\end{tabular}

Stroke prevention Phase III in $A F$

ROCKET-AF [18] Warfarin $(14,264)$

J-ROCKET [19] Warfarin (1280) 
TABLE 3.I (continued)

\begin{tabular}{lll}
\hline Clinical condition & Trial & Comparator (n) \\
\hline $\begin{array}{l}\text { Acute coronary } \\
\text { syndrome }\end{array}$ & Phase II & \\
& & \\
& ATLAS-ACS & Placebo (3500) \\
& TIMI-46 [20] & \\
& Phase III & \\
& ATLAS-ACS 2 & Placebo $(15,526)$ \\
& TIMI-51 [21] & \\
$\begin{array}{l}\text { VTE prevention } \\
\text { in medically ill } \\
\text { patients }\end{array}$ & Phase III & \\
& & \\
& MAGELLAN & Enoxaparin (8101) \\
\end{tabular}

Data from [6-23]

$A F$ atrial fibrillation, $L M W H$ low-molecular-weight heparin, $V K A$ vitamin $\mathrm{K}$ antagonist, $V T E$ venous thromboembolism

any deep vein thrombosis (DVT) (proximal or distal), nonfatal objectively confirmed pulmonary embolism (PE) and all-cause mortality; safety was judged on the basis of major hemorrhage incidence. A pooled analysis of two of these studies confirmed non-inferiority of rivaroxaban in patients undergoing elective THR or TKR, with no significant dose-response relationship for efficacy but with a significant dose-related increase for the primary safety endpoint $(P<0.001)$, a total daily dose of $5-20 \mathrm{mg}$ being the optimal dose range (Fig. 3.2) [9, 25].

Consequently, a fixed dose of rivaroxaban $10 \mathrm{mg}$ qd was selected to be used in the phase III RECORD (REgulation of Coagulation in ORthopedic surgery to prevent DVT and PE) program (Table 3.2) [9-12]. The RECORD program included four large trials that recruited more than 12,500 patients undergoing elective THR or TKR. All RECORD trials have the composite primary efficacy endpoint of DVT, 


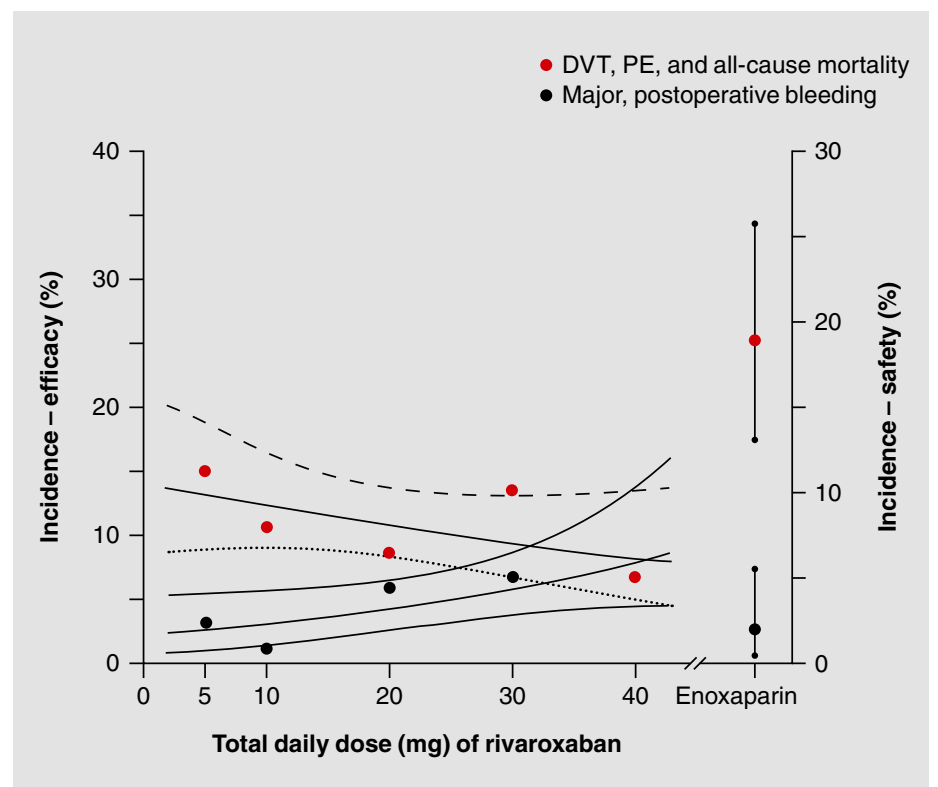

FIGURE 3.2 Dose-response relationships between rivaroxaban and primary efficacy and safety endpoint. Results for the prevention of venous thromboembolism after major orthopedic surgery. $D V T$ deep vein thrombosis, $P E$ pulmonary embolism (Reproduced with permission from Eriksson et al. [8])

nonfatal PE, or all-cause mortality, and the main secondary efficacy endpoint was major VTE. The primary safety endpoint was major hemorrhage. These studies had no upper age limit and allowed recruitment of patients with mild or moderate hepatic impairment.

The RECORD1 and the RECORD3 studies compared rivaroxaban $10 \mathrm{mg}$ qd (starting $6-8 \mathrm{~h}$ after surgery) with enoxaparin $40 \mathrm{mg}$ qd (starting the evening before surgery) both given for 31-39 days (extended prophylaxis) after THR (RECORD1) [9] or for 10-14 days (short-term prophylaxis) after TKR (RECORD3) [11]. In both studies treatment with rivaroxaban was significantly superior to enoxaparin for VTE 


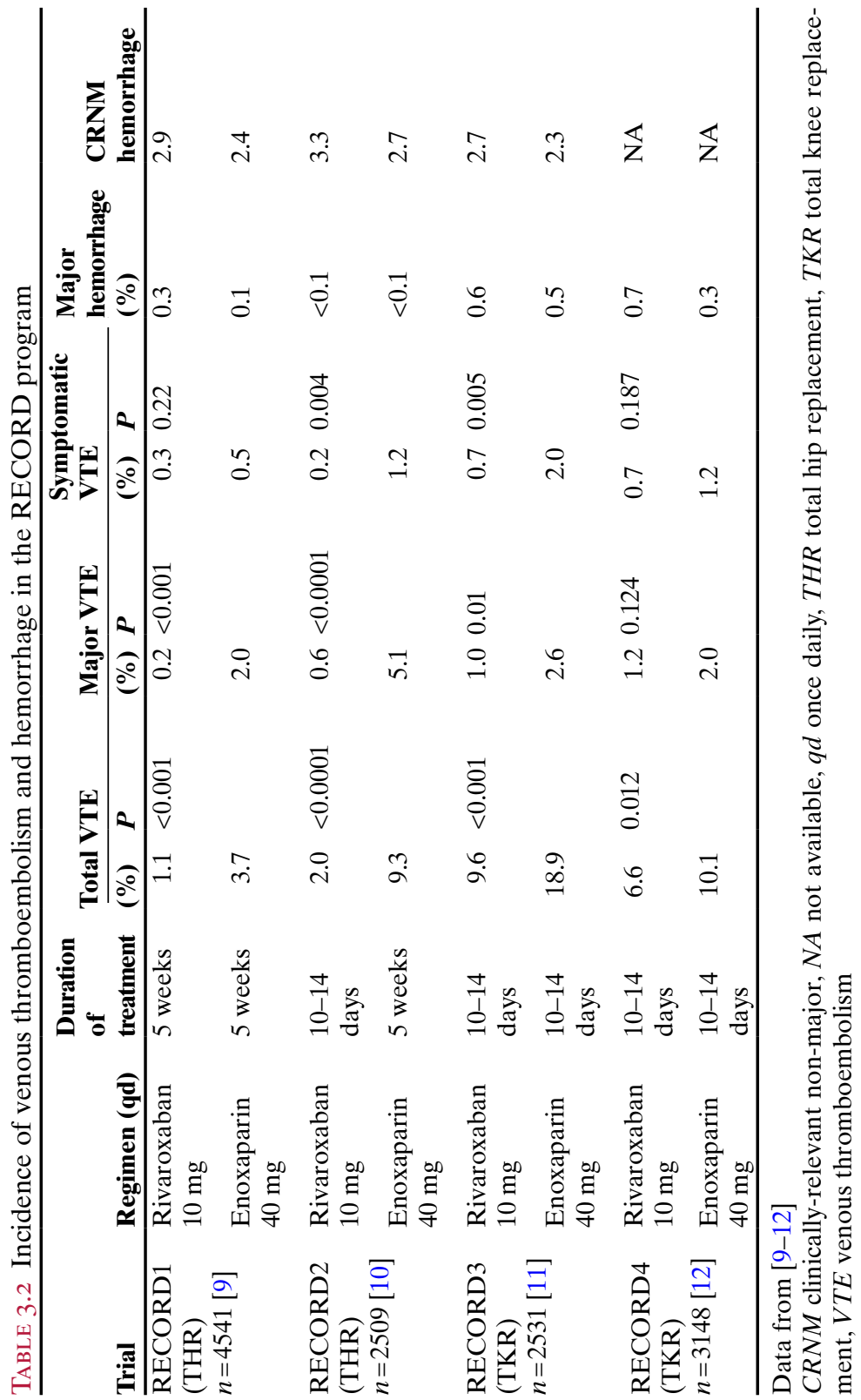


prevention (Table 3.2). Recognizing that current guidelines recommend extended prophylaxis for patients undergoing THR, although this is not done in many countries, the RECORD2 trial investigated the efficacy and safety of extended thromboprophylaxis with rivaroxaban (5 weeks) compared with short-term enoxaparin $40 \mathrm{mg}$ qd for 10-14 days [10]. The study demonstrated that prolonged prophylaxis with rivaroxaban was associated with reduced incidence of VTE, including symptomatic events, after THR. Of note, despite administration of rivaroxaban for 3 weeks longer than enoxaparin, the rate of major hemorrhage at 5 weeks was low and similar in both groups.

In the RECORD4 trial rivaroxaban $10 \mathrm{mg}$ was significantly more effective than the North American regimen of enoxaparin $30 \mathrm{mg}$ bid (10-14 days) for the prevention of VTE in patients undergoing TKR, with similar rates of major hemorrhage for both treatments and no serious liver toxicity with rivaroxaban [12]. Thus, the superiority of rivaroxaban over enoxaparin for VTE prevention was demonstrated in all four studies, with a good safety profile. As a result, in 2008 rivaroxaban received approval in the European Union (EU) and in Canada for the prevention of VTE in patients undergoing elective THR or TKR surgery. In July 2011, the FDA approved rivaroxaban for prophylaxis of DVT in adults undergoing hip and knee replacement surgery.

The utility of rivaroxaban (10 $\mathrm{mg}$ qd for up to 5 weeks) for VTE prevention in hospitalized medically ill patients was assessed in the phase III MAGELLAN study, with shortterm enoxaparin (10 days followed by placebo) as the comparator [22]. At day 10, the primary efficacy outcome (composite asymptomatic proximal DVT, symptomatic DVT, symptomatic non-fatal PE and VTE-related death) occurred in $2.7 \%$ of patients in both treatment groups, demonstrating the non-inferiority of rivaroxaban $(P=0.003)$. At study end (day 35) fewer patients treated with rivaroxaban had the primary outcome ( $4.4 \%$ vs $5.7 \% ; P=0.02$ for superiority). However, there was an increase in the risk of clinically relevant bleeding in the rivaroxaban group (4.1\% vs $1.7 \%$; $P<0.0001$ ) [23]. 


\subsubsection{Treatment of Venous Thromboembolism}

The initial phase IIb ODIXa-DVT [13] and EINSTEIN-DVT [14] studies (Table 3.3) assessed the clinical efficacy and safety of rivaroxaban for the treatment of VTE in patients with acute, symptomatic, proximal DVT without symptomatic PE. The treatment was administered for 3 months, with openlabel standard therapy (low-molecular-weight heparin/heparin following vitamin $\mathrm{K}$ antagonist [VKA]) as comparator.

In the ODIXa-DVT study, rivaroxaban doses 10,20 , or $30 \mathrm{mg}$ bid, or $40 \mathrm{mg}$ qd, were tested [13]. The primary efficacy endpoint of reduced thrombus burden on day 21 (assessed by quantitative compression ultrasonography) without recurrent VTE or VTE-related death was reported in 43.8-59.2\% of patients receiving rivaroxaban and in $45.9 \%$ of patients receiving standard therapy. The incidence of the primary safety endpoint (major hemorrhage) was $1.7-3.3 \%$ in the rivaroxaban groups; there were no events in the standard therapy group.

In the EINSTEIN-DVT study [14], therapy with rivaroxaban $20-40 \mathrm{mg}$ qd was associated with an incidence of 5.4$6.6 \%$ for the primary endpoint (the composite of symptomatic, recurrent VTE, and deterioration of thrombotic burden, as assessed by compression ultrasound and perfusion lung scan) compared with $9.9 \%$ in the standard therapy group. The primary safety endpoint (any clinically relevant hemorrhage) developed in 2.9-7.5\% of patients receiving rivaroxaban and $8.8 \%$ of those on the standard therapy, with no evidence of compromised liver function in those receiving rivaroxaban.

Of note, the phase II studies revealed that the twice-daily rivaroxaban regimen was more effective for thrombus regression at 3 weeks, whereas the once- and twice-daily regimens showed similar effectiveness at 3-month follow-up [13]. Accordingly, an initial intensified twice-daily regimen (rivaroxaban $15 \mathrm{mg}$ bid for 3 weeks) followed by long-term $20 \mathrm{mg}$ qd dosing was chosen for investigation in the phase III EINSTEIN studies: EINSTEIN-DVT, EINSTEIN-PE, and EINSTEIN- EXTENSION [15-17]. 
TABLE 3.3 Clinical efficacy and safety of rivaroxaban for the treatment of venous thromboembolism

EINSTEIN-DVT study

Rivaroxaban
20 mg qd
$(n=1731)$

Standard therapy

$(n=1718)$

Symptomatic recurrent

$36 / 1731(2.1)$

$51 / 1718(3.0)$

VTE, $\mathrm{n} / \mathrm{N}(\%)$

First major bleeding or

$139 / 1718(8.1)$

$138 / 1711(8.1)$

clinically relevant non-

major bleeding, $\mathrm{n} / \mathrm{N}$ (\%)

EINSTEIN-PE study

Rivaroxaban
20 mg qd
$(n=2419)$

Standard therapy

$(n=2413)$

Symptomatic recurrent

$50 / 2419(2.1)$

44/2413 (1.8)

VTE, n/N (\%)

First major or clinically

249/2412 (10.3)

274/2405 (11.4)

relevant non-major

bleeding, n/N (\%)

EINSTEIN-Ext study

$\begin{array}{ll}\text { Rivaroxaban } & \text { Placebo } \\ 20 \text { mg qd } & (n=594) \\ (n=602) & \end{array}$

Recurrent VTE,

$8 / 602$ (1.3)

42/594 (7.1)

(composite of DVT or non-fatal or fatal PE), $\mathrm{n} / \mathrm{N}(\%)$

First major bleeding or $36 / 602(6.0)$

$7 / 594$ (1.2)

clinically relevant non-major

bleeding, $\mathrm{n} / \mathrm{N}$ (\%)

Data from [15-17]

$D V T$ deep vein thrombosis, $L M W H$ low-molecular-weight heparin, $P E$ pulmonary embolism, $q d$ once daily, $V K A$ vitamin $\mathrm{K}$ antagonist, $V T E$ venous thromboembolism 
EINSTEIN-DVT was an open-label, randomized, eventdriven, non-inferiority study that compared oral rivaroxaban (15 mg bid for 3 weeks, followed by $20 \mathrm{mg} \mathrm{qd}$ ) against subcutaneous enoxaparin followed by a VKA for 3,6 , or 12 months in patients with acute, symptomatic DVT [14]. In parallel, EINSTEIN-EXTENSION was a double-blind, randomized, event-driven superiority study that compared rivaroxaban alone (20 mg qd) with placebo for an additional 6 or 12 months in patients who had completed 6-12 months of treatment for VTE $[15,17]$. The primary efficacy outcome for both studies was recurrent VTE. The principal safety outcome for EINSTEIN-DVT was major bleeding or clinically-relevant non-major (CRNM) bleeding in the initial-treatment study and major bleeding in the continued-treatment study. The study recruited 3449 patients: 1731 in the rivaroxaban arm and 1718 in the conventional management arm [15]. Rivaroxaban was non-inferior with respect to the primary efficacy outcome while the principal safety outcome occurred in $8.1 \%$ of the patients in each group (Table 3.3). In the extended-treatment study, which included 602 patients in the rivaroxaban group and 594 in the placebo group, rivaroxaban had superior efficacy. Four patients in the rivaroxaban group had nonfatal major bleeding $(0.7 \%)$, versus none in the placebo group $(P=0.11)$ (Table 3.3) [15].

In the randomized, open-label, event-driven, non-inferiority EINSTEIN-PE trial, 4832 subjects with acute symptomatic PE with or without DVT were assigned to either rivaroxaban (15 mg bid for 3 weeks, followed by $20 \mathrm{mg} \mathrm{qd}$ ) or to standard therapy with enoxaparin followed by dose-adjusted VKA for 3,6 , or 12 months [16]. The trial demonstrated that rivaroxaban was non-inferior to standard therapy for the primary efficacy outcome symptomatic recurrent VTE $(2.1 \%$ versus $1.8 \%$, respectively, $P=0.003$ for non-inferiority margin) (Table 3.3). Also, $10.3 \%$ of patients treated with rivaroxaban developed the principal safety outcome of major or CRNM bleeding versus $11.4 \%$ in those on standard care $(P=0.23)$, thus suggesting that fixed-dose rivaroxaban can be an effective and safe therapeutic option in PE. 
In December 2011 rivaroxaban received approval by the European Commission for treatment of DVT and prevention of recurrent DVT and PE following an acute DVT in adults. Additionally, in November 2012 rivaroxaban was approved by the FDA for DVT, PE and prevention of recurrent DVT and PE following initial treatment.

\subsubsection{Stroke Prevention in Atrial Fibrillation}

In terms of numbers of patients, stroke prevention in atrial fibrillation (AF) is potentially the largest indication that may benefit from the non-VKA oral anticoagulants (NOACs). The rising incidence of AF in a progressively aging population suggests that millions of people may eventually require life-long anticoagulant therapy to prevent severely disabling complications. The ROCKET AF study investigated the effectiveness and safety of rivaroxaban $20 \mathrm{mg}$ qd $(15 \mathrm{mg}$ qd in those with moderate kidney impairment) versus warfarin for the prevention of stroke or systemic embolism in 14,264 patients with non-valvular AF (NVAF) who were at an increased risk for stroke [18]. Rivaroxaban was non-inferior to warfarin for the prevention of stroke or systemic embolism (hazard ratio [HR] in the rivaroxaban group, $0.79 ; 95 \% \mathrm{CI}, 0.66-0.96 ; P<0.001$ for non-inferiority). Moreover, there was no significant between-group difference in the risk of major bleeding, although intracranial and fatal bleeding occurred less frequently in the rivaroxaban group [18]. In the J-ROCKET AF study conducted in Japan, a lower dose of rivaroxaban (15 mg qd; $5 \mathrm{mg}$ qd for patients with moderate renal impairment) was shown to be non-inferior to warfarin for the prevention of stroke or systemic embolism [19].

In November 2011, in view of the results of the ROCKET AF study, rivaroxaban was approved by the FDA for the prevention of stroke and systemic embolism in patients with NVAF, at a dose of $20 \mathrm{mg}$ (or $15 \mathrm{mg}$ if creatinine clearance 15-50 $\mathrm{ml} / \mathrm{min}$ ) qd. In December 2011, rivaroxaban was 
approved by the European Commission for prevention of stroke and systemic embolism in adult patients with NVAF with one or more risk factors.

\subsubsection{Acute Coronary Syndromes}

In the phase IIb ATLAS ACS-TIMI 46 (Anti-Xa Therapy to Lower cardiovascular events in Addition to aspirin with/ without thienopyridine therapy in Subjects with Acute Coronary Syndrome) study, 3491 patients with recent acute coronary syndrome (ACS) were randomized to escalating total daily doses of rivaroxaban, ranging from $5 \mathrm{mg}$ up to $20 \mathrm{mg}$ (qd or bid), or placebo, in addition to the standard antiplatelet therapy of aspirin or aspirin plus a thienopyridine (eg, clopidogrel) for secondary prevention of cardiovascular events [20]. Patients on the rivaroxaban regimens had higher rates of hemorrhage than those on placebo, and the risk increased in a dose-dependent manner; however, no study arm was stopped due to increased hemorrhage. A strong trend towards reduction in cardiovascular events was observed with rivaroxaban, which reduced the main secondary efficacy endpoint of death, myocardial infarction, or stroke compared with placebo $(P=0.0270)$. Two doses of rivaroxaban were tested in the phase III ATLAS ACS 2 TIMI 51 study [21]. The study assigned 15,526 patients with a recent ACS to receive either $2.5 \mathrm{mg}$ bid or $5 \mathrm{mg}$ bid of rivaroxaban or placebo for a mean of 13 months and up to 31 months. The primary efficacy endpoint was a composite of death from cardiovascular causes, myocardial infarction, or stroke. The investigators concluded that in patients with a recent ACS, rivaroxaban reduced the risk of the composite endpoint ( $8.9 \%$ versus $10.7 \%, P=0.008)$ but increased the risk of major bleeding $(2.1 \%$ versus $0.6 \%, P<0.001)$ and intracranial hemorrhage $(0.6 \%$ versus $0.2 \%, P=0.009)$ although not the risk of fatal bleeding [21].

Based on the results of the ATLAS ACS 2 TIMI-51 trial rivaroxaban $2.5 \mathrm{mg}$ bid was approved by the European 
Commission based on a positive from the EMA Committee for Medicinal Products for Human Use (CHMP) in March 2013 for secondary prevention of ACS.

\subsection{Apixaban}

Apixaban is another potent, highly selective, and reversible inhibitor of factor $\mathrm{Xa}$ and is active against both free enzyme and factor $\mathrm{Xa}$ bound within the prothrombinase complex (Fig. 3.3). The bioavailability of apixaban after oral absorption is over $50 \%$ [26]. Peak plasma levels of apixaban are observed $3 \mathrm{~h}$ after administration and plasma concentrations reach the steady state by day 3 . The half-life of apixaban is

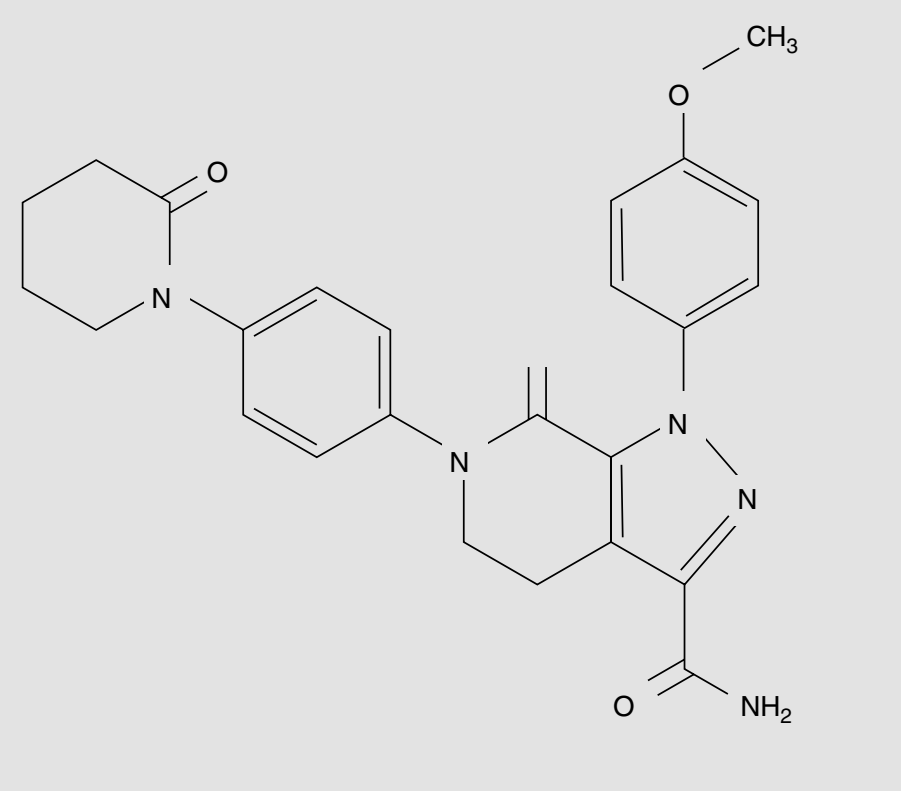

Figure 3.3 Apixaban 
between 8 and $15 \mathrm{~h}$, which allows twice-daily administration of the drug. The primary elimination route is fecal, with only about $25 \%$ eliminated via the kidney. Apixaban has little effect on the prothrombin time at therapeutic concentrations, but plasma levels can be assessed using a factor Xa inhibition assay. The clinical development program of apixaban is summarized in Table 3.4 [27-39].

\subsubsection{Venous Thromboembolism Prevention in Major Orthopedic Surgery}

In a randomized phase II dose-response clinical trial in 1238 patients undergoing TKR, apixaban 5, 10, or $20 \mathrm{mg}$ /day (administered qd or bid) was compared with enoxaparin (30 mg bid) and open-label warfarin [27]. Apixaban and enoxaparin were started 12-24 h after surgery; the warfarin dose was titrated from the evening of the day of surgery. After 10-14 days of the treatment, bilateral venography was performed and patients were further treated at the attending physician's discretion. The primary endpoint, a composite of VTE events plus all-cause mortality at 42-day follow-up, was significantly lower in the compound apixaban group $(8.6 \%)$ than in the enoxaparin $(15.6 \%, P<0.02)$ or warfarin $(26.6 \%$, $P<0.001)$ groups. The primary endpoint rates for apixaban $2.5 \mathrm{mg}$ bid $(9.9 \%)$ and $5.0 \mathrm{mg}$ qd $(11.3 \%)$ were lower than in the enoxaparin $(15.6 \%)$ and warfarin group $(26.6 \%)$. The incidence of major hemorrhage in apixaban-treated patients was low and ranged from 0 (2.5 $\mathrm{mg}$ bid) to $3.3 \%$ (20 $\mathrm{mg} \mathrm{qd})$, with comparable results for once- and twice-daily administration. No major hemorrhage was observed in the enoxaparin and warfarin groups [27].

The clinical utility of apixaban for VTE prevention after major joint surgery was investigated in the phase III ADVANCE program (Table 3.4). In two multicenter, randomized, double-blind, active-controlled clinical trials (ADVANCE-1 and ADVANCE-2), the safety and efficacy of oral apixaban $(2.5 \mathrm{mg}$ bid) versus enoxaparin $(30 \mathrm{mg}$ bid in 
TABLE 3.4 Clinical development of apixaban

\begin{tabular}{lll}
\hline Clinical condition & Trial & Comparator (n) \\
\hline $\begin{array}{l}\text { VTE prevention } \\
\text { following joint } \\
\text { surgery }\end{array}$ & Phase II & \\
& & \\
& APROPOS [27] & $\begin{array}{l}\text { Warfarin or } \\
\text { Enoxaparin (1238) }\end{array}$ \\
& Phase III & \\
& ADVANCE-1 & Enoxaparin (3195) \\
& {$[28]$} & \\
& ADVANCE-2 & Enoxaparin (3057) \\
& {$[29]$} & \\
& ADVANCE-3 & Enoxaparin (5407) \\
& {$[30]$} & \\
& Phase II & \\
& Botticelli trial & Heparin/VKA (520) \\
& {$[31]$} & \\
& Phase III & \\
AMPLIFY [32] & Enoxaparin + Warfarin \\
& & (5400) \\
& AMPLIFY-Ext & Placebo (2486) \\
& {$[33]$} &
\end{tabular}

Stroke prevention in Phase III atrial fibrillation

AVERROES Aspirin (5599) [34]

ARISTOTLE Warfarin $(18,201)$ [35]

Acute coronary Phase II syndrome
APPRAISE
Placebo (1715)

[36] 
TABLE 3.4 (continued)

\begin{tabular}{lll}
\hline Clinical condition & Trial & Comparator (n) \\
\hline $\begin{array}{l}\text { Prevention of VTE in } \\
\text { medically ill patients }\end{array}$ & Phase III & \\
& APPRAISE-2 & Placebo (7392) \\
& {$[37]$} & \\
& ADOPT [38] & Enoxaparin (6528) \\
VTE prevention in & Phase II & \\
cancer patients & & \\
& ADVOCATE & Placebo (125) \\
& {$[39]$} & \\
\hline
\end{tabular}

Data from [27-39]

$V T E$ venous thromboembolism

ADVANCE-1 and $40 \mathrm{mg}$ qd in ADVANCE-2) for preventing DVT and PE after TKR was evaluated in 3195 patients in ADVANCE-1 and 3057 patients in ADVANCE-2 (Table 3.5) $[28,29]$. The duration of treatment was 12 days and the primary outcome of both studies was defined as a combination of asymptomatic and symptomatic DVT, nonfatal PE and all-cause mortality. In ADVANCE-1, apixaban did not meet the pre-specified statistical criteria for non-inferiority versus enoxaparin, but its use was associated with lower rates of clinically relevant bleeding and it had a similar adverse-event profile [28]. In ADVANCE-2, apixaban $2.5 \mathrm{mg}$ bid, starting the morning after TKR, offered a more effective orally administered alternative to $40 \mathrm{mg}$ per day enoxaparin (relative risk $0.62 ; 95 \% \mathrm{CI} 0.51-0.74 ; P<0.0001)$, without increased bleeding rates (Table 3.5) [29].

Similarly, in the ADVANCE-3 trial, the efficacy and safety of 5-week administration of apixaban (2.5 mg bid) in comparison with enoxaparin in the prevention of DVT and PE was assessed in 5407 patients after THR. Patients were randomized to receive apixaban plus placebo or enoxaparin plus placebo for 5 weeks. The primary outcome was again a combination of asymptomatic and symptomatic DVT, nonfa- 


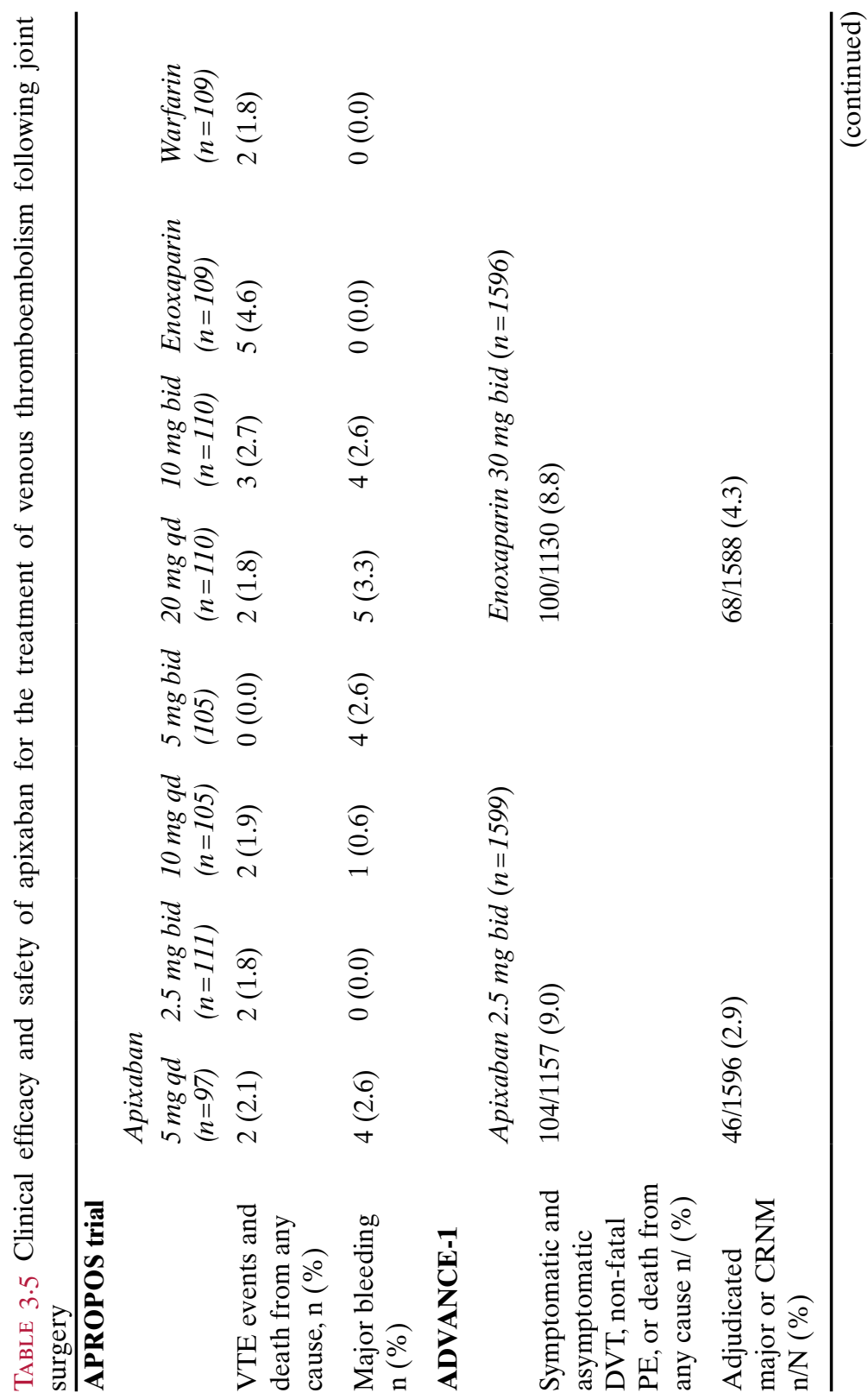


42 Chapter 3. Factor Xa Inhibitors

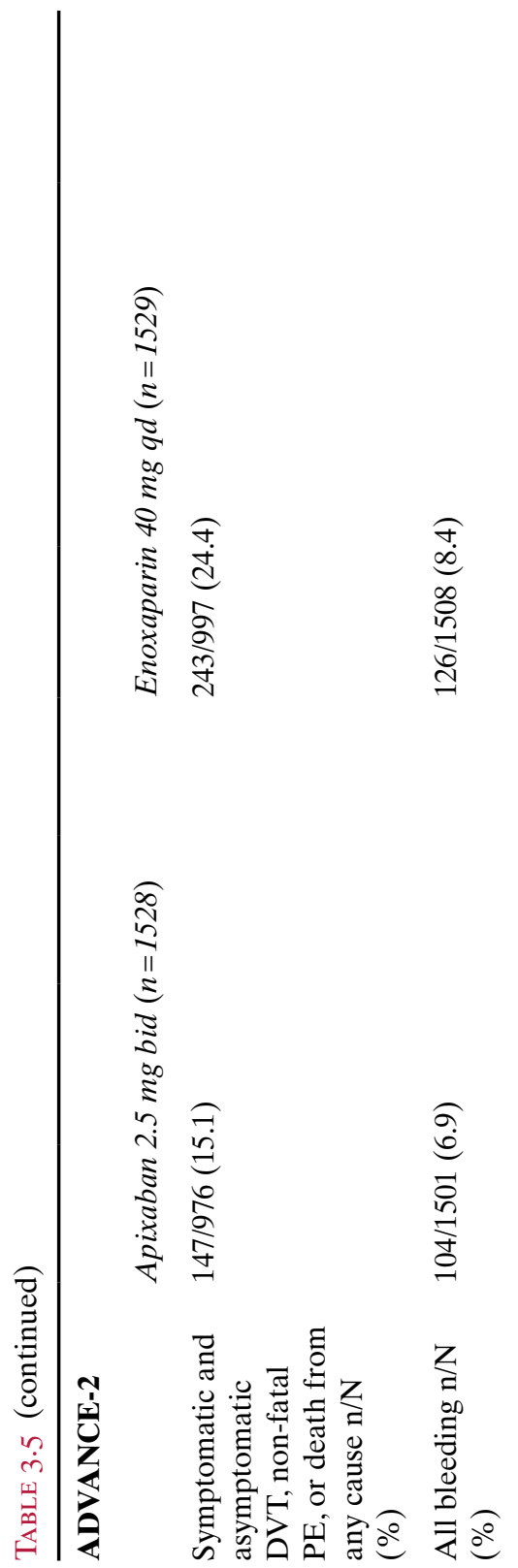



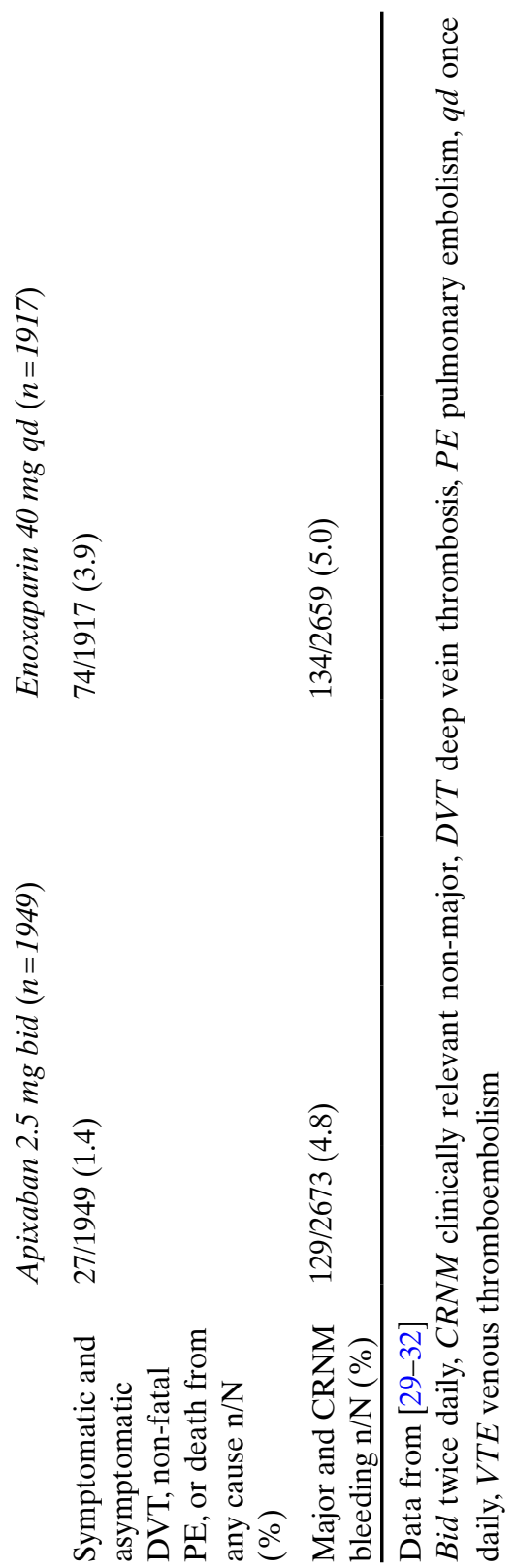
tal PE, and all-cause mortality. The ADVANCE-3 investigators concluded that, among patients undergoing hip replacement, apixaban was associated with lower rates of VTE without increased bleeding compared with subcutaneous enoxaparin (relative risk with apixaban, 0.36; $95 \% \mathrm{CI}$, $0.22-0.54 ; P<0.001$ for both non-inferiority and superiority) (Table 3.5) [30].

Apixaban received approval in the EU for the prevention of VTE in patients undergoing elective THR or TKR surgery in May 2011. In March 2014 apixaban was approved by the FDA for the prevention of VTE following hip or knee replacement surgery.

\subsubsection{Stroke Prevention in Atrial Fibrillation}

Two phase III clinical trials assessed apixaban for stroke prevention in patients with AF. In the first, the AVERROES study, the effectiveness of oral apixaban $(5 \mathrm{mg}$ bid; or $2.5 \mathrm{mg}$ in selected patients) was compared with aspirin (81-324 mg qd) for 36 months in the prevention of stroke or systemic embolism in 5599 patients with permanent or persistent AF who had at least one additional risk factor for stroke but could not be treated with VKA (Table 3.6) [34]. The data and safety monitoring board recommended early termination of the study because of a clear benefit in favor of apixaban. Apixaban compared with aspirin, reduced the risk of stroke or systemic embolism (1.6\% versus $3.7 \%$ per year, respectively, $P<0.001)$ without significantly increasing the risk of major bleeding or intracranial hemorrhage [34].

The second phase III trial, the ARISTOTLE study, investigated whether apixaban ( $5 \mathrm{mg}$ bid) was as effective as warfarin in preventing stroke and systemic embolism in 18,201 patients with AF who had at least one additional risk factor for stroke [35]. The primary efficacy endpoint was the composite outcome of stroke or systemic embolism. In ARISTOTLE, apixaban reduced the risk of stroke or systemic embolism by $21 \%$ compared with warfarin. The reduction was significant 
$(P<0.01)$ and supported the superiority of apixaban over warfarin for the primary outcome of preventing stroke or systemic embolism. Apixaban also reduced all-cause mortality by $11 \%$ and major bleeding by $31 \%$ (Table 3.6) [35]. Apixaban has become the first new oral anticoagulant superior to warfarin in reducing stroke or systemic embolism, all-cause mortality, and major bleeding in patients with AF. Apixaban received approval by the European Commission for the prevention of stroke and systemic embolism in patients with non-valvular AF in November 2012 and by the FDA in December 2012.

\subsubsection{Thromboprophylaxis in Other Clinical Settings}

Apixaban is being tested in several additional settings, which may expand the use of oral anticoagulation beyond currently established indications. The phase II randomized ADVOCATE study has been designed to determine the tolerability, effectiveness, and safety of apixaban in prevention of thrombolic events in patients with advanced or metastatic cancer on prescribed chemotherapy for more than 90 days [39]. In this randomized double-blind study 12-week administration of apixaban $(5,10$, or $20 \mathrm{mg} \mathrm{qd}, n=95$ overall) was compared with placebo $(n=30)$. The primary outcome was either major bleeding or CRNM bleeding and secondary outcomes included VTE and grade III or higher adverse events related to the study drug. Although the study appeared to show a favorable safety profile for apixaban, it was underpowered to draw any reliable conclusions and further phase III evaluation of apixaban in this setting would be appropriate [39].

A further phase III randomized trial, ADOPT, compared the safety and efficacy of apixaban with enoxaparin in preventing DVT and PE in patients hospitalized with congestive heart failure, acute respiratory failure, infection (without septic shock), acute rheumatic disorder, or inflammatory bowel disease [38]. A total of 6528 subjects underwent randomization, 4495 of whom could be evaluated for the primary efficacy outcome: 2211 in the 
TABLE 3.6 Clinical efficacy and safety of apixaban for stroke prevention in atrial fibrillation

AVERROES trial

$\begin{array}{ll}\text { Apixaban } & \text { Aspirin } \\ 5 \text { mg bid } & 81-324 \text { mg qd } \\ (n=2808) & (n=2791)\end{array}$

Occurrence of stroke

51/2808 (1.6) 113/2791 (3.7)

(ischemic or hemorrhagic)

or systemic embolism, $\mathrm{n} / \mathrm{N}$

$(\% / y)$

Major Bleeding, $\mathrm{n} / \mathrm{N}(\% / \mathrm{y})$

$44 / 2808(1.4)$

$39 / 2791(1.2)$

ARISTOTLE trial

$\begin{array}{ll}\text { Apixaban } & \text { Warfarin } \\ \text { mg bid } & (n=9081)\end{array}$

Occurrence of stroke or

212/9120 (1.3) 265/9081 (1.6)

systemic embolism, $\mathrm{n} / \mathrm{N}$

$(\% / y)$

Major bleeding, $\mathrm{n} / \mathrm{N}(\% / \mathrm{y}) \quad 327 / 9088$ (2.1) $\quad 462 / 9052$ (3.1)

Data from $[34,35]$

bid twice daily, $q d$ once daily

apixaban group and 2284 in the enoxaparin group. The primary outcome was the composite of VTE or VTE-related death, whereas secondary outcome measures included all-cause mortality, major hemorrhage, and CRNM hemorrhage. Among the patients who could be evaluated, $2.71 \%$ in the apixaban group and $3.06 \%$ in the enoxaparin group met the criteria for the primary efficacy outcome (relative risk with apixaban, 0.87 ; $95 \%$ CI, $0.62-1.23 ; P=0.44$ ). Major bleeding occurred in $0.47 \%$ of the patients in the apixaban group and in $0.19 \%$ of the patients in the enoxaparin group. The investigators therefore concluded that in medically ill patients, an extended course of thromboprophylaxis with apixaban was not superior to a shorter course with enoxaparin and was associated with significantly more major bleeding events than was enoxaparin [38]. 


\subsubsection{Treatment of Venous Thrombosis}

Investigation of the utility of apixaban for the treatment of patients with VTE started with the phase II Botticelli DVT dose-ranging clinical trial [31]. In this study 520 patients with symptomatic DVT were randomized to receive apixaban (5 mg or $10 \mathrm{mg}$ bid or $20 \mathrm{mg} \mathrm{qd}$ ) or traditional treatment with LMWH or fondaparinux followed by VKA. After management for 84-91 days, no significant difference was reported between the treatments in the rate of occurrence of the primary outcome, a composite of symptomatic recurrent VTE and asymptomatic deterioration of bilateral compression ultrasound or perfusion lung scan $(4.7 \%$ for apixaban and $4.2 \%$ in control patients) [31]. The primary outcome rates for the tested apixaban doses were $6.0 \%$ for $5 \mathrm{mg}$ bid, $5.6 \%$ for $10 \mathrm{mg}$ bid, and $2.6 \%$ for $20 \mathrm{mg}$ qd. The principal safety outcome (a composite of major and CRNM hemorrhage) developed at a similar rate in the apixaban-treated patients $(7.3 \%)$ and the control group $(7.9 \%)$. The principal safety outcome rates for the tested apixaban doses were $8.6 \%$ for $5 \mathrm{mg}$ bid, $4.5 \%$ for $10 \mathrm{mg}$ bid, and $7.3 \%$ for $20 \mathrm{mg} \mathrm{qd}$.

In the Phase III randomized, multicenter AMPLIFY study [32] apixaban was compared with the conventional treatment (enoxaparin/warfarin) in 5395 patients with VTE. Patients randomized to apixaban received $10 \mathrm{mg}$ bid for 7 days followed by $5 \mathrm{mg}$ bid for 6 months. The primary outcome was the rate of symptomatic, recurrent VTE and related deaths; the principal safety outcomes were major bleeding alone and major bleeding plus CRNM bleeding. The results from the AMPLIFY study found apixaban to be non-inferior to conventional therapy, with symptomatic recurrent VTE occurring in $2.3 \%$ of patients in the apixaban group and $2.7 \%$ of patients who received conventional therapy (relative risk, 0.84; $P<0.001$ ) (Table 3.7). Rates of VTE or cardiovascular (CV)-related death and VTE or all-cause death were lower in patients who received apixaban compared with those who received standard therapy. Moreover, apixaban resulted in significantly less major bleeding ( $0.6 \%$ vs $1.8 \% ; P<0.001$ for superiority). 
TABLE 3.7 Clinical efficacy and safety of apixaban in the prevention of recurrent VTE

Botticelli trial

$$
\begin{aligned}
& \text { Apixaban LMWH/VKA } \\
& 5 \mathrm{mg} \text { bid } \quad 10 \mathrm{mg} \quad 20 \mathrm{mgqd}(n=128) \\
& (n=130) \quad \text { bid } \quad(n=128) \\
& (n=134)
\end{aligned}
$$

Symptomatic $7(6.0) \quad 7(5.6) \quad 3(2.6) \quad 5(4.2)$

recurrent

VTE and

symptomatic

deterioration

in the

thrombotic

burden, n (\%)

$\begin{array}{lllll}\text { Major and } \quad 11(8.6) & 6(4.5) & 11(8.9) & 10(7.9)\end{array}$

clinically

relevant

non-major

bleeding

AMPLIFY study

$$
\text { Apixaban }(n=2691) \quad \begin{aligned}
& \text { Enoxaparin } / V K A \\
& (n=2635)
\end{aligned}
$$

First recurrent $59(2.3)$

$71(2.7)$

VTE or VTE-

related death,

n (\%)

Major

$15(0.6)$

$49(1.8)$

bleeding, $\mathrm{n}$

(\%)

Clinically

$103(3.8)$

$215(8.0)$

relevant

non-major

bleeding $\mathrm{n}$,

(\%) 
AMPLIFY-Ext study

$\begin{array}{lll}\text { Apixaban } & \text { Apixaban } & \text { Placebo }(n=829) \\ 2.5 \mathrm{mg} \text { bid } & 5 \mathrm{mg} \text { bid } & \\ (n=840) & (n=813) & \end{array}$

Symptomatic $32(3.8) \quad 34(4.2) \quad 96(11.6)$

recurrent

VTE or death

from any

cause, n (\%)

Major bleeding, $2(0.2) \quad 1(0.1) \quad 4(0.5)$

$\mathrm{n}(\%)$

Data from [31-33]

bid twice daily, $L M W H$ low-molecular weight heparin, $q d$ once daily, $V K A$ vitamin $\mathrm{K}$ antagonist, $V T E$ venous thromboembolism

Additionally, the AMPLIFY-EXT trial assessed the efficacy and safety of apixaban in preventing VTE recurrence or death in 2486 patients with clinical diagnosis of DVT or PE who had completed 6-12 months of standard treatment for DVT or PE or had completed treatment with apixaban or enoxaparin and warfarin as participants in the AMPLIFY trial [33]. Patients received apixaban (2.5 or $5 \mathrm{mg}$ bid) or placebo for 12 months. The study found that VTE or related death occurred in $8.8 \%$ of patients who received placebo, as compared with $1.7 \%$ who received apixaban $2.5 \mathrm{mg}$ (95\% CI 5.0-9.3) and $1.7 \%$ apixaban $5 \mathrm{mg}$ (95\% CI 4.9-9.1; $P<0.001$ for both). There were fewer significant events of primary outcome with the both apixaban $2.5 \mathrm{mg}$ (relative risk 0.33 [95\% CI 0.22-0.48]) and $5 \mathrm{mg}$ (relative risk 0.36 [95\% CI 0.25-0.53]) compared with placebo (Table 3.7). Bleeding results from the AMPLIFY-Extension study showed that both apixaban $2.5 \mathrm{mg}$ and $5 \mathrm{mg}$ doses were associated with low bleeding levels that were similar to placebo [33].

Based on the results of the AMPLIFY and AMPLIFY-Ext studies in June 2014 apixaban was approved in the EU for the treatment and prevention of DVT and PE. Following this 
approval in August 2014, apixaban $2.5 \mathrm{mg}$ and $5 \mathrm{mg}$ was approved by the FDA for the treatment of recurrent DVT and PE following initial therapy.

\subsubsection{Acute Coronary Syndrome}

The phase II APPRAISE-1 clinical trial evaluated the safety of apixaban in 1715 patients with recent ACS. Patients were randomized to receive apixaban $(2.5 \mathrm{mg}$ bid or $10.0 \mathrm{mg} \mathrm{qd})$ or placebo for 26 weeks. The primary outcome was the incidence of major or CRNM hemorrhage; the secondary outcome was a composite of cardiovascular death, nonfatal myocardial infarction, severe recurrent ischemia, or ischemic stroke. The investigators reported a dose-related increase in bleeding compared with placebo (apixaban $2.5 \mathrm{mg}$ bid: HR, 1.78; 95 \% CI 0.91-3.48; $P=0.09 ; 10$ mg qd: HR, 2.45; $95 \%$ CI, $1.31-4.61 ; P=0.005)$ and a trend toward a reduction in ischemic events with the addition of apixaban to antiplatelet therapy in patients with recent ACS [36]. Whether apixaban could improve outcomes in patients after an ACS was further investigated in the phase III trial APPRAISE-2. This trial was a randomized, double-blind, placebo-controlled clinical trial comparing apixaban, at a dose of $5 \mathrm{mg}$ bid, with placebo, in addition to standard antiplatelet therapy, in patients with a recent ACS and at least two additional risk factors for recurrent ischemic events. The trial was terminated prematurely due to an increase in major bleeding events with apixaban in the absence of a counterbalancing reduction in recurrent ischemic events [37].

\subsection{Edoxaban}

Edoxaban (Fig. 3.4) is a potent, highly selective factor $\mathrm{Xa}$ inhibitor with a high affinity for free factor $\mathrm{Xa}\left(\mathrm{K}_{\mathrm{i}} 0.56\right.$ $\mathrm{nM}$ ) and for factor Xa bound to the prothrombinase complex $\left(\mathrm{K}_{\mathrm{i}} 2.98 \mathrm{nM}\right)$ [40]. It has predictable and consistent 


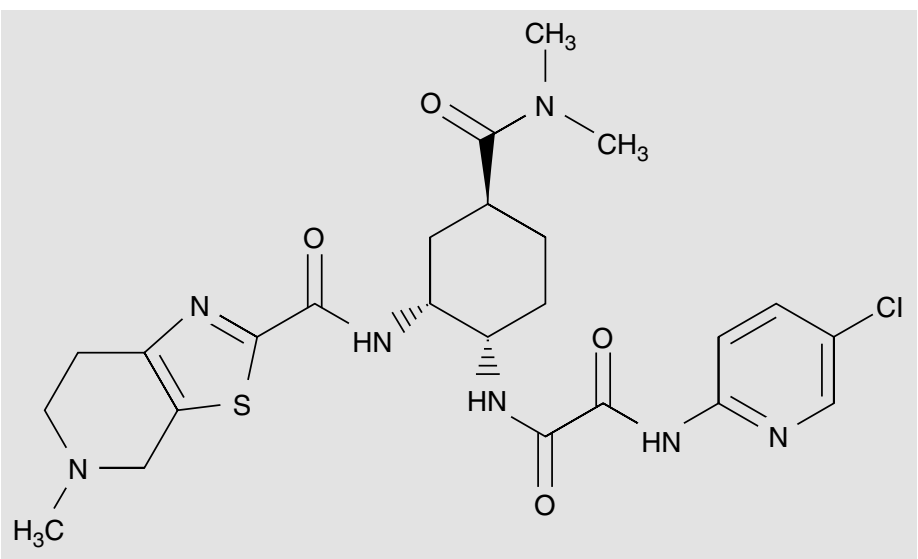

Figure 3.4 Edoxaban

pharmacokinetics with dose proportional increases in plasma concentrations, and a half-life of approximately 10-14 h [10, 41, 42]. Additionally, edoxaban has a rapid onset of action and high oral bioavailability (61.8 \%), reaching maximum plasma concentrations $1-2 \mathrm{~h}$ after administration, and inhibition of thrombin formation over $\sim 24 \mathrm{~h}$, supporting once-daily dosing [10, 12, 43]. Moreover, edoxaban is mainly metabolized via hydrolysis, whereas CYP450 enzymes play an insignificant role.

Around $35 \%$ of the given dose is eliminated via the kidneys [44], indicating the importance of the kidneys in the excretion of edoxaban. Consequently, studies have evaluated edoxaban in patients with renal impairment and suggest that in patients with chronic kidney disease, edoxaban exposure is increased and a lower dose is appropriate [45].

The pharmacokinetics of edoxaban are not influenced by gender, age, ethnicity, or food intake, although small but clinically insignificant changes in pharmacokinetics after a high fat meal or in the elderly is observed [10,46]. Edoxaban has minimal drug interactions, however like all factor Xa inhibitors, edoxaban is a substrate of P-glycoprotein (P-gp) and there- 
fore has potential for interaction with strong P-gp inhibitors. As such, a $50 \%$ dose reduction to edoxaban $30 \mathrm{mg}$ is recommended when concomitantly used with the P-gp inhibitors, ciclosporin, dronedarone, erythromycin, or ketoconazole. In contrast no dose adjustment is necessary with amiodarone, quinidine or verapamil [47]. The predicable pharmacokinetic and pharmacodynamics profiles of edoxaban allows for its use without regular laboratory monitoring [10].

Similar to other factor Xa inhibitors, currently there is no antidote for edoxaban. However a recently completed phase I study evaluated the effects of PER977 on bleeding following administration of edoxaban to healthy subjects (clinicaltrials. gov identifier NCT01826266) [48]. PER977 was found to be effective in restoring baseline hemostasis 10-30 min after administration of 100-300 mg PER977, this effect was sustained for $24 \mathrm{~h} \mathrm{[49].} \mathrm{An} \mathrm{additional} \mathrm{phase} \mathrm{II} \mathrm{study} \mathrm{is} \mathrm{underway} \mathrm{investi-}$ gating the re-anticoagulation effect of edoxaban following reversal by PER977 (clinicaltrials.gov identifier NCT02207257) [50]. This trial also aims to identify a dose regimen of PER977 that is able to reverse the effects of edoxaban for $21 \mathrm{~h}$.

Edoxaban was approved in Japan for prevention of VTE following lower-limb orthopedic surgery and in the US for the prevention of stroke and systemic embolic events (SEE) in NVAF and for the treatment of PE and DVT and prevention of recurrent VTE [51]. Edoxaban received European approval in June 2015 following a positive opinion from the CHMP for the use of edoxaban for the prevention of AF related stroke and treatment of PE and DVT and prevention of recurrent VTE [52]. The clinical development of edoxaban can be seen in Table 3.8.

\subsubsection{Venous Thromboembolism Prevention in Major Orthopedic Surgery}

Two phase II dose-finding studies, 011 [54] and J04 [53], investigated the use of edoxaban for the prevention of VTE after joint replacement. Study J04 was a placebo controlled 
TABLE 3.8 Clinical development program for edoxaban

\section{Clinical condition}

VTE prophylaxis

following joint surgery

\section{Trial}

Stroke prevention in atrial fibrillation
Phase II

Study J04 [53]

Study $011[54]$

Phase III

STARS E-III [55] Enoxaparin (716)

STARS J-IV [56] Enoxaparin (92)

STARS J-V [57] Enoxaparin (610)

Comparator (n)

Placebo (523)

Dalteparin (774)

Phase II

Study 018 [58] Warfarin (1146)

Phase III

ENGAGE AF-TIMI Warfarin $(21,105)$ $48[59,60]$

Phase III

Hokusai-VTE [61, 62] Warfarin (8292)

Data from [53-62]

$V T E$ venous thromboembolism

study that evaluated edoxaban $5,15,30$, or $60 \mathrm{mg}$ qd for prevention of VTE following TKR in Japanese patients [53]. Patients were treated for 11-14 days following surgery. There was a significant, dose-dependent reduction in the incidence of VTE with edoxaban compared with placebo, with a comparable risk of bleeding across all treatment groups with no significant differences among edoxaban doses or between edoxaban and placebo.

In the double-blind, active-controlled, multicenter 011 study, 903 patients were randomized to receive oral edoxaban $(15,30,60$, or $90 \mathrm{mg}$ od) or subcutaneous dalteparin qd 
(initial dose 2500 IU, subsequent doses 5000 IU) [54]. Both medications were started 6-8 h after surgery and administered for 7-10 days. Data from 776 participants were included into the primary efficacy analysis. The primary efficacy endpoint of total VTE was significantly lower in subjects treated with edoxaban $(28.2 \%, 21.2 \%, 15.2 \%$, and $10.6 \%$ for edoxaban $15,30,60$, and $90 \mathrm{mg}$, respectively) than in those receiving dalteparin $(43.8 \%, P<0.005)$ (Table 3.9$)$.

The open-label STARS J-IV [56] trial investigated the safety and efficacy of edoxaban in preventing VTE after major joint surgery in 92 Japanese patients undergoing hip fracture surgery. Patients were randomized to either edoxaban $30 \mathrm{mg}$ qd (6-24 h post-surgery) or enoxaparin $2000 \mathrm{IU}$ bid (24-36 h after surgery). The primary endpoints were bleeding events and secondary events included thromboembolic events and adverse events. STARS J-IV found that treatment with edoxaban was as safe and efficacious as enoxaparin treatment, and major or CRNM bleeding occurred less often in the edoxaban group compared with the enoxaparin group (3.4\% and $6.9 \%$ respectively). However, thromboembolic events occurred more often in the edoxaban group $(6.5 \%$ vs $3.7 \%$ ) (Table 3.9$)$.

Two pivotal, randomized, double-blind, multicenter, phase III trials compared edoxaban $30 \mathrm{mg}$ qd to enoxaparin in knee surgery, STARS E-III [55], and hip surgery, STARS J-V [57]. In both STARS E-III and STARS J-V edoxaban $30 \mathrm{mg} \mathrm{qd}$ was superior to enoxaparin in the preventions of VTE, with comparable rates of bleeding $[55,57]$. Supported by the data from these phase III studies edoxaban was approved in Japan in April 2011 for the prevention of VTE following lower-limb orthopedic surgery.

A post-marketing vigilance report [63] recorded all spontaneously reported adverse drug reactions (ADR) that occurred following the launch of edoxaban in Japan, from July 2011 to January 2012. During this time approximately 20,000 patients had been treated with edoxaban. A total of 67 ADR were reported in 57 patients, the majority of ADR were bleeding events, 15 of which were serious. Most ADR occurred in the first week of treatment and none were fatal. 
TABLE 3.9 Clinical efficacy and safety of edoxaban in prevention of VTE following major joint surgery

Study J04

$\begin{array}{lllll}\text { Edoxaban } & & & \begin{array}{l}\text { Placebo } \\ (n=102)\end{array} \\ 5 \mathrm{mg} & 15 \mathrm{mg} & 30 \mathrm{mg} & 60 \mathrm{mg} & (\mathrm{n}) \\ q d & q d & q d & q d & \\ (n=103) & (n=106) & (n=103) & (n=106)\end{array}$

Incidence of

$$
\begin{array}{llllll}
\text { Incidence of } & 26 & 24 & 11 & 8(9.1) & 43(48.3) \\
\text { VTE, n (\%) } & (29.5) & (26.1) & (12.5) & & \\
\text { Major and } & 2(1.9) & 4(3.8) & 4(3.9) & 5(4.7) & 4(3.9)
\end{array}
$$

Major and

CRNM bleeding,

\begin{tabular}{|c|c|c|c|c|c|}
\hline \multirow[b]{3}{*}{$\begin{array}{l}\text { Incidence of } \\
\text { total VTE, n/N } \\
(\%)\end{array}$} & \multicolumn{4}{|c|}{ Edoxaban } & \multirow{2}{*}{$\begin{array}{l}\text { Dalteparin } \\
(n=172)\end{array}$} \\
\hline & $\begin{array}{l}15 \mathrm{mg} \\
q d \\
(n=192)\end{array}$ & $\begin{array}{l}30 \mathrm{mg} \\
q d \\
(n=170)\end{array}$ & $\begin{array}{l}60 \mathrm{mg} \\
q d \\
(n=185)\end{array}$ & $\begin{array}{l}90 m g \\
q d \\
(n=177)\end{array}$ & \\
\hline & $\begin{array}{l}48 / 170 \\
(28.2)\end{array}$ & $\begin{array}{l}32 / 151 \\
(21.2)\end{array}$ & $\begin{array}{l}24 / 158 \\
(15.2)\end{array}$ & $\begin{array}{l}16 / 151 \\
(10.6)\end{array}$ & $63 / 144(43.8$ \\
\hline \multirow{3}{*}{$\begin{array}{l}\text { Major and } \\
\text { CRNM bleeding, } \\
\text { n (\%) } \\
\text { STARS E-III }\end{array}$} & $\begin{array}{l}3 / 192 \\
(1.6)\end{array}$ & $\begin{array}{l}3 / 170 \\
(1.8)\end{array}$ & $\begin{array}{l}4 / 185 \\
(2.2)\end{array}$ & $\begin{array}{l}4 / 177 \\
(2.3)\end{array}$ & 0/172 (0.0) \\
\hline & & & & & \\
\hline & \multicolumn{3}{|c|}{$\begin{array}{l}\text { Edoxaban } 30 \mathrm{mg} q d \\
(n=354)\end{array}$} & \multicolumn{2}{|c|}{$\begin{array}{l}\text { Enoxaparin } 20 \mathrm{mg} \\
\text { bid }(n=349)\end{array}$} \\
\hline $\begin{array}{l}\text { Symptomatic } \\
\text { PE, and } \\
\text { symptomatic and } \\
\text { asymptomatic } \\
\text { DVT, n/N (\%) }\end{array}$ & \multicolumn{3}{|c|}{ 22/299 (7.4) } & \multicolumn{2}{|c|}{ 41/295 (13.9) } \\
\hline $\begin{array}{l}\text { Major and } \\
\text { CRNM bleeding, } \\
\text { n/N (\%) }\end{array}$ & \multicolumn{3}{|c|}{$22 / 354(6.2)$} & \multicolumn{2}{|c|}{$13 / 349(3.7)$} \\
\hline
\end{tabular}
n $(\%)$

Study 011 
STARS J-IV

$$
\begin{array}{ll}
\text { Edoxaban } 30 \mathrm{mg} \text { qd } & \text { Enoxaparin } \\
(n=59) & 2000 \mathrm{IU}(n=29)
\end{array}
$$

Major and

2/59 (3.4)

$2 / 29(6.9)$

CRNM Bleeding, n (\%)

Thromboembolic

$3 / 46(6.5)$

events, $\mathrm{n} / \mathrm{N}$ (\%)

STARS J-V

Edoxaban $30 \mathrm{mg}$ qd $(n=303)$

6/255 (2.4)
Enoxaparin $20 \mathrm{mg}$ bid $(n=301)$

$17 / 248(6.9)$

Composite of symptomatic and asymptomatic DVT, and PE, $\mathrm{n} / \mathrm{N}(\%)$

Major and CRNM 8/303 (2.6)

bleeding, $\mathrm{n} / \mathrm{N}(\%)$

Data from [53-57]

bid twice daily, $C R N M$ clinically relevant non-major, $D V T$ deep vein thrombosis, $P E$ pulmonary embolism, $q d$ once daily, $V T E$ venous thromboembolism

The post-marketing analysis found that in the real-life setting the safety profile of edoxaban was consistent with that found in clinical trials and no unforeseen safety signals were observed.

\subsubsection{Stroke Prevention in Atrial Fibrillation}

In a parallel-group, active controlled phase II study the safety of four fixed-dose regimens of edoxaban were compared with warfarin in 1146 patients with NVAF. Patients were random- 
ized to edoxaban $30 \mathrm{mg}$ od, $60 \mathrm{mg}$ od, $30 \mathrm{mg}$ bid, $60 \mathrm{mg}$ bid, or warfarin (INR 2.0-3.0) [58]. A significantly higher incidence of major and/or CRNM bleeding was seen in the twicedaily edoxaban regimen (60 mg bid, $10.6 \%, P=0.002 ; 30 \mathrm{mg}$ bid, $7.8 \%, P=0.029)$ than warfarin $(3.2 \%)$, however there were no significant differences between the warfarin and once-daily regimens. For the same total daily dose of edoxaban, $60 \mathrm{mg}$, the $30 \mathrm{mg}$ bid dose was associated with a trend towards an increase in major bleeding plus CRNM bleeding compared with $60 \mathrm{mg}$ qd $(P=0.08)$. This study concluded that treatment with edoxaban 30 or $60 \mathrm{mg}$ qd was safe and well tolerated.

A pooled pharmacokinetic analysis [64] was performed on data from 15 phase I and II studies which aimed to characterize edoxaban population pharmacokinetics. Using an exposure-response analysis (in which $\mathrm{C}_{\min }$ was the best predictor of bleed probability), a $50 \%$ dose reduction in selected patients was recommended, especially in patients with renal impairment, concomitant use of P-gp inhibitors, and body weight $\leq 60 \mathrm{~kg}$. Consequently, two doses of edoxaban (30 mg and $60 \mathrm{mg}$ od) were selected for investigation in the phase III ENGAGE AF-TIMI 48 trial.

The ENGAGE AF-TIMI 48 study [59] investigated the safety and efficacy of two doses of edoxaban compared with warfarin. A total 21,105 patients with a history of AF were enrolled into the study making this the largest study of a NOAC in patients with AF to date. Patients were randomized to edoxaban $60 \mathrm{mg}$ qd $(n=7012)$, edoxaban $30 \mathrm{mg} \mathrm{qd}$ $(n=7002)$ or warfarin $(n=7012$; median time in therapeutic range, $68.4 \%$ ). In the edoxaban group, patients with moderate renal impairment (creatinine clearance $[\mathrm{CrCl}] 30-50 \mathrm{~mL} /$ $\min$ ), weight $\leq 60 \mathrm{~kg}$ or who were receiving select P-gp inhibitors had a $50 \%$ dose reduction. Median follow-up duration was 2.8 years. The primary efficacy objective was the noninferiority of edoxaban compared with warfarin in the prevention of stroke and SEE, key secondary outcomes included a composite of stroke, SEE or death from CV causes, major adverse cardiac events (MACE), and stroke, SEE or death [59]. 


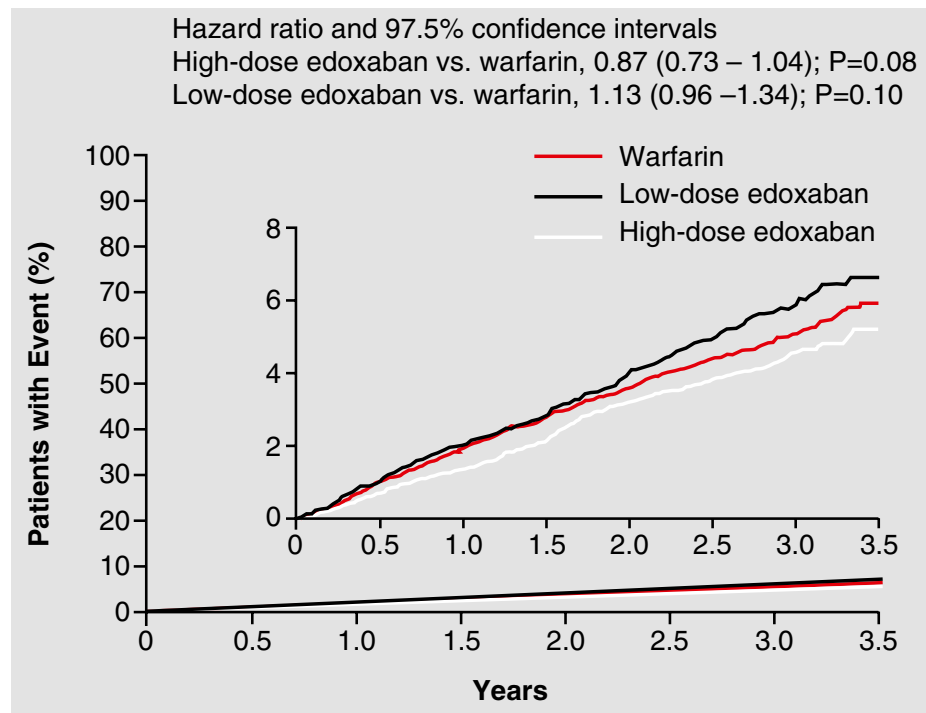

FIgure 3.5 Kaplan-Meier curve for stroke of systemic embolic events in ENGAGE AF-TIMI 48 (Reproduced with permission from Giugliano et al. [60])

The primary safety outcome was major bleeding during treatment. The primary efficacy endpoint occurred in 232 patients treated with warfarin $(1.50 \% / y), 182$ patients treated with edoxaban $60 \mathrm{mg}$ qd $(1.18 \% / \mathrm{y}$; HR vs warfarin $0.79,95 \% \mathrm{CI}$ $0.63-0.99 ; P<0.001$ for non-inferiority), and 253 patients treated with edoxaban $30 \mathrm{mg}$ qd (1.61 \%/y; HR vs warfarin $1.07 .95 \%$ CI $0.87-1.31 ; P=0.005$ for non-inferiority). Additionally, ENGAGE AF-TIMI 48 met the pre-specified criteria for noninferiority and both doses were compared with warfarin in a test for superiority. For patients treated with warfarin the annualized rate of the primary endpoint was $1.80 \%$ compared with $1.57 \%$ in the edoxaban $60 \mathrm{mg}$ qd group (HR 0.87, CI 0.73-1.08; $P=0.08$ ), and $2.04 \%$ in the edoxaban $30 \mathrm{mg}$ qd group (HR 1.13, CI $0.96-1.34 ; P=0.10$ ) (Fig. 3.5) [60].

The primary safety endpoint of major bleeding occurred in 524 patients in the warfarin group $(3.43 \% / y)$, compared with 


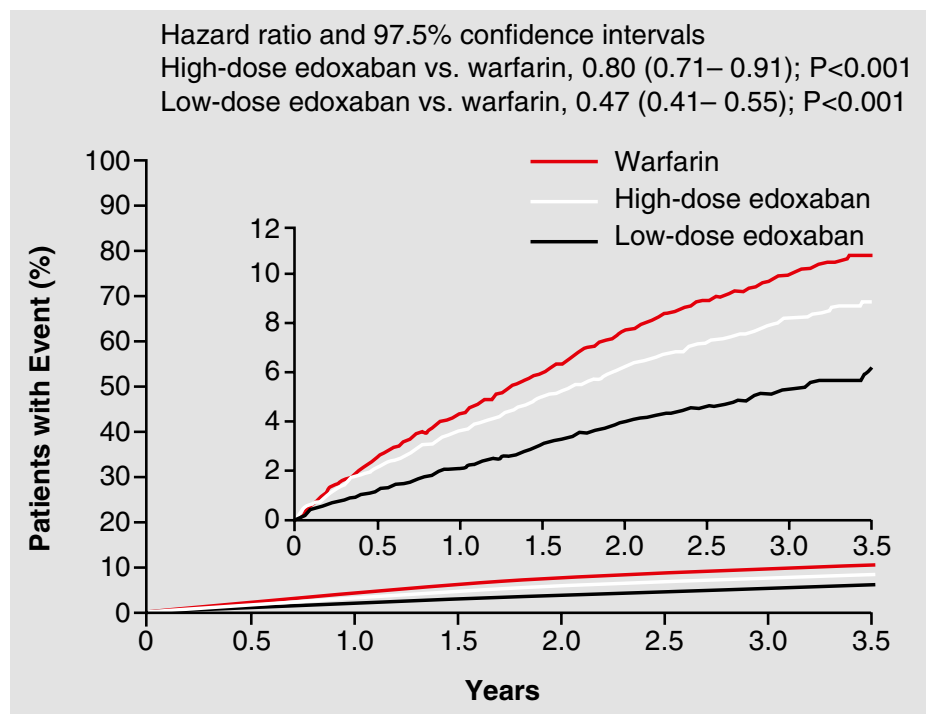

FIgURE 3.6 Kaplan-Meier curve for major bleeding events in ENGAGE AF-TIMI 48 (Reproduced with permission from Giugliano et al. [60])

418 patients in the edoxaban $60 \mathrm{mg}$ qd group $(2.75 \% / \mathrm{y} ; \mathrm{HR}$ $0.80 ; 95 \% \mathrm{CI}, 0.71-0.91 ; P<0.001)$, and 254 patients in the edoxaban $30 \mathrm{mg}$ qd group (1.61 \%/y; HR, 0.47; $95 \% \mathrm{CI}$, $0.41-0.55 ; P<0.001$ ) (Fig. 3.6) [60]. The rates of all three prespecified secondary outcomes were significantly lower with edoxaban $60 \mathrm{mg}$ than with warfarin.

Based on the findings from ENGAGE AF-TIMI 48, edoxaban $60 \mathrm{mg}$ was approved by the FDA in January 2015 for the prevention of stroke and SEE in NVAF. According to the label given by the FDA edoxaban $60 \mathrm{mg}$ should be dose reduced to $30 \mathrm{mg}$ in patients with a $\mathrm{CrCl} 15-30 \mathrm{~mL} / \mathrm{min}$ and should not be used in patients with $\mathrm{CrCl}>95 \mathrm{~mL} / \mathrm{min}$ due to increased risk of ischemic stroke compared with warfarin. In ENGAGE AF-TIMI 48, $77 \%$ of patients had a $\mathrm{CrCl}<95 \mathrm{~mL} /$ min [52]. Additionally, edoxaban received European approval following a positive opinion from the CHMP for the use of 
edoxaban in Europe in patients with NVAF, which did not include a limitation according to renal function [52]. Edoxaban has also been approved in Japan and Switzerland for prevention of ischemic stroke and systemic embolism in patients with AF.

\subsubsection{Treatment of Venous Thromboembolism}

The phase III, event-driven, randomized, double-blind, double-dummy, parallel-group, multinational study Hokusai-VTE [61, 62] investigated the safety and efficacy of edoxaban in prevention of VTE. The design of Hokusai-VTE aimed to broaden the applicability of edoxaban use in VTE treatment to real world practice, and encourage enrolment of a broad type of patients, including those with extensive disease [61]. Hokusai-VTE allowed for variable treatment duration from 3 to 12 months, regardless of treatment duration all patients were observed for 12 months [61].

A total of 8292 patients were randomized to receive openlabel heparin (for $\geq 5$ days) followed by either edoxaban $60 \mathrm{mg}$ qd (started after discontinuation of heparin) or warfarin (started concurrently with heparin and until INR 2.0-3.0). A $50 \%$ dose adjustment occurred in the edoxaban group at randomization and any point during the study in patients with moderate renal impairment $(\mathrm{CrCl} 30-50 \mathrm{~mL} / \mathrm{min})$, weight $\leq 60 \mathrm{~kg}$ or who were receiving select P-gp inhibitors. HokusaiVTE was unique in that dose adjustment not only occurred at randomization but could occur at any point during the study as necessary. Additionally, the flexible treatment duration is unique to Hokusai-VTE, which is unusual in clinical trials but is more in line with clinical practice. The primary efficacy endpoint was symptomatic recurrent VTE during the 12 month study period and the objective of the study was to determine the non-inferiority of heparin follow by edoxaban compared with heparin followed by warfarin. The secondary endpoints included a composite of symptomatic recurrent DVT, nonfatal symptomatic recurrent PE and all-cause mortality, and a 


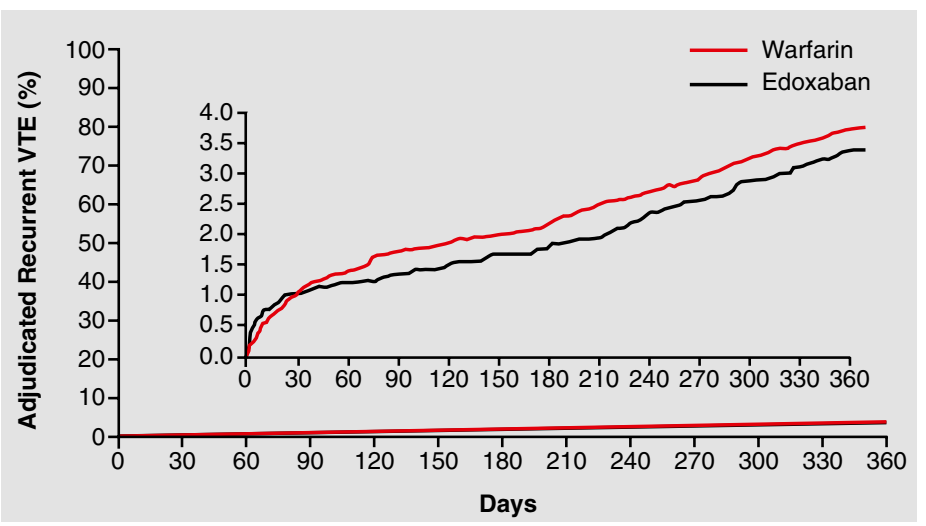

FIgURE 3.7 Kaplan-Meier cumulative event rates for the symptomatic recurrent VTE in Hokusai-VTE (Reproduced with permission from The Hokusai-VTE Investigators [62])

composite clinical outcome of symptomatic recurrent DVT, non-fatal symptomatic recurrent PE, and CV mortality. The primary safety endpoint was major or CRNM bleeding, secondary endpoints included all deaths, major adverse cardiovascular events, liver enzyme and bilirubin abnormalities. Over the 12 month study period edoxaban was found to be non-inferior to warfarin for the primary outcomes; symptomatic recurrent VTE occurred in $3.2 \%$ of patients in the edoxaban group and $3.5 \%$ of patients in the warfarin group (HR $0.89 ; 95 \%$ CI, $0.70-1.13 ; P<0.001$ for non-inferiority) (Fig. 3.7).

Additionally, Hokusai-VTE analyzed events that occurred on-treatment. Symptomatic recurrent VTE occurred in $1.6 \%$ of the edoxaban group and $1.9 \%$ of the warfarin group (HR, 0.82; $95 \%$ CI, 0.60-1.14; $P<0.001$ for non-inferiority). In a pre-specified analysis of patients that required dose adjustment edoxaban was also found to be non-inferior to warfarin, with events occurring in $3.0 \%$ and $4.2 \%$, respectively (HR, $0.73 ; 05 \%$ CI, 0.42-1.26). In the subgroup of patients with PE and evidence of right ventricular dysfunction (N-terminalprohormone of brain natriuretic peptide level of $\geq 500 \mathrm{pg} / \mathrm{mL}$ ), 


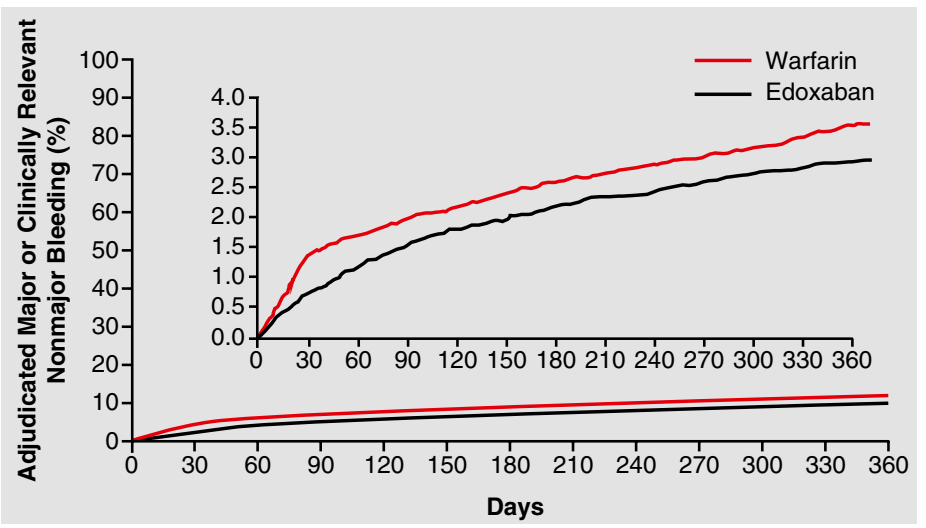

FIGURE 3.8 Kaplan-Meier curve of major of clinically relevant nonmajor bleeding events in Hokusai-VTE (Reproduced with permission from The Hokusai-VTE investigators [62])

recurrent VTE occurred in $3.3 \%$ of patients $(15 / 454)$ in the edoxaban group and in $6.2 \%$ of patients $(30 / 484)$ in the warfarin group (HR, 0.52; $95 \%$ CI, 0.28-0.98). Similar results were observed among patients with right ventricular dysfunction as assessed by means of computed tomography (HR, 0.42; $95 \%$ CI, 0.15-1.20). During the 12 month study period the primary safety outcome occurred in $8.5 \%$ of the edoxaban group and $10.3 \%$ of the warfarin group (HR, $0.81 ; 95 \% \mathrm{CI}$, $0.71-0.94 ; P=0.004$ for superiority) demonstrating that edoxaban caused significantly less bleeding than warfarin (Fig. 3.8).

In the pre-specified analyses of the dose adjusted edoxaban patients first major or CRNM bleeding occurred in $7.9 \%$ of edoxaban patients and $12.8 \%$ of warfarin patents (HR, 0.62 ; $95 \%$ CI, 0.44-0.86).

In January 2015, based on the results from Hokusai-VTE, edoxaban $60 \mathrm{mg}$ was approved in the US for the treatment of DVT and PE following 5-10 days parenteral heparin. In patients with $\mathrm{CrCl} 30-50 \mathrm{~mL} / \mathrm{min}$, body weight $\leq 60 \mathrm{~kg}$ and patients receiving concomitant $\mathrm{P}$-gp inhibitors edoxaban $60 \mathrm{mg}$ should be reduced to $30 \mathrm{mg}$ [52]. Additionally, based 
on data from Hokusai-VTE edoxaban was recommended by the CHMP for the treatment of DVT and PE and prevention of recurrent PE and DVT in adults [52]. Edoxaban has also been approved in Japan and Switzerland for VTE treatment and secondary prevention.

\subsection{Emerging Factor Xa Inhibitors}

Currently, the factor Xa inhibitor betrixaban (PRT-054021) is in phase III clinical development for the prevention of thromboembolism and the partial factor IXa inhibitor TTP889 is in phase II development for the prevention of VTE reflecting interest in the high clinical potential of this pharmaceutical group (Table 3.10) [65-67]. Enrollment has begun for a phase I study to assess the safety, tolerability, pharmacokinetics and pharmacodynamics of the direct factor Xa inhibitor GCC-4401C compared with placebo and rivaroxaban (clinicaltrials.gov identifier NCT01954238) [68].

\subsubsection{Betrixaban}

Betrixaban (PRT-054021) specifically and reversibly inhibits factor Xa with a $\mathrm{K}_{\mathrm{i}}$ of $0.117 \mathrm{nmol} / \mathrm{L}$. It has a bioavailability of $47 \%$, a half-life of $19 \mathrm{~h}$, and is excreted almost unchanged in bile. Betrixaban has demonstrated antithrombotic activity in animal models and in human blood. it is well tolerated in healthy individuals across a wide range of doses. Betrixaban has been investigated in phase II trials for VTE prevention in patients after major joint surgery (EXPERT) [65] and for stroke prevention in patients with AF (EXPLORE-Xa) [66]. Currently a phase III double-blind trial of betrixaban is recruiting patients, with the aim of enrolling $~ 6850$ patients, to evaluate the extended treatment (35-42 days) of oral betrixaban in hospitalized patients compared with standard treatment of enoxaparin (clinicaltrials.gov identifier NCT01583218) [69]. Primary efficacy endpoint is a composite 
TABLE 3.IO Clinical development of emerging factor Xa inhibitors

\begin{tabular}{|c|c|c|c|}
\hline $\begin{array}{l}\text { Clinical } \\
\text { condition } \\
\end{array}$ & \multicolumn{2}{|c|}{ Phase Trial title } & $\begin{array}{l}\text { Comparator } \\
\text { (n) }\end{array}$ \\
\hline \multicolumn{4}{|c|}{ Betrixaban (PRT054021) } \\
\hline $\begin{array}{l}\text { Extended } \\
\text { VTE } \\
\text { prevention }\end{array}$ & III & $\begin{array}{l}\text { Acute medically ill VTE } \\
\text { prevention with extended } \\
\text { duration Betrixaban } \\
\text { Study (The APEX Study) }\end{array}$ & $\begin{array}{l}\text { Enoxaparin } \\
(6850)\end{array}$ \\
\hline $\begin{array}{l}\text { VTE } \\
\text { prevention } \\
\text { in major } \\
\text { joint surgery }\end{array}$ & II & $\begin{array}{l}\text { Factor Xa inhibitor, } \\
\text { PRT054021, against } \\
\text { Enoxaparin for the } \\
\text { Prevention of Venous } \\
\text { Thromboembolic Events } \\
\text { (EXPERT) [65] }\end{array}$ & $\begin{array}{l}\text { Enoxaparin } \\
(200)\end{array}$ \\
\hline $\begin{array}{l}\text { Stroke } \\
\text { prevention } \\
\text { in atrial } \\
\text { fibrillation }\end{array}$ & II & $\begin{array}{l}\text { Study of the safety, } \\
\text { tolerability and pilot } \\
\text { efficacy of oral factor } \\
\text { Xa inhibitor betrixaban } \\
\text { compared with warfarin } \\
\text { (EXPLORE-Xa) [66] }\end{array}$ & Warfarin (500) \\
\hline \multicolumn{4}{|l|}{ TTP889 } \\
\hline $\begin{array}{l}\text { VTE } \\
\text { prevention }\end{array}$ & & $\begin{array}{l}\text { Partial factor IXa } \\
\text { inhibition with TTP } 889 \\
\text { for prevention of venous } \\
\text { thromboembolism: an } \\
\text { exploratory study [67] }\end{array}$ & Placebo (260) \\
\hline
\end{tabular}

Data from [65-67]

$V T E$ venous thromboembolism

of asymmetrical proximal DVT, symptomatic DVT, non-fatal PE, or VTE-related death through day 35, primary safety outcome is major bleeding [70].

\subsubsection{TTP889}

TTP889 is a small-molecule, orally available selective factor IXa antagonist with a dose-dependent inhibition of factor IXa $\approx 90 \%$ [67] and a half-life between 21 and $25 \mathrm{~h}$ [71]. In an 
exploratory study of the antithrombotic potential of TTP889, 260 patients, who had hip fracture repair and who and had received LMWH or unfractionated heparin for thromboprophylaxis 5-9 days after surgery, were randomized to receive TTP889 $300 \mathrm{mg}$ or placebo. No significant differences in the number of total VTE events were observed, and no major bleeding occurred [67] Further studies are warranted [67, 71].

\section{References}

1. Kakar P, Watson T, Lip GYH. Drug evaluation: rivaroxaban, an oral, direct inhibitor of activated factor X. Curr Opin Investig Drugs. 2007;8:256-65.

2. Kubitza D, Becka M, Wensing G, et al. Safety, pharmacodynamics, and pharmacokinetics of BAY 59-7939 - an oral, direct factor Xa inhibitor - after multiple dosing in healthy male subjects. Eur J Clin Pharmacol. 2005;61:873-80.

3. Gruber A, Marzec UM, Buetehorn U, Hanson S, Perzborn E. Potential of activated prothrombin complex concentrate and activated Factor vII to reverse the anticoagulant effects of rivaroxaban in primates. Blood (ASH Annual Meeting Abstracts). 2008;112:1307:abstract 3825.

4. Perzborn E, Trabandt A, Selbach K, Tinel H. Prothrombin complex concentrate reverses the effects of high-dose rivaroxaban in rats. J Thromb Haemost. 2009;7:379:abstract pp-mo-183.

5. Perzborn E, Roehrig S, Straub A, Kubitza D, Misselwitz F. The discovery and development of rivaroxaban, an oral, direct factor Xa inhibitor. Nat Rev Drug Discov. 2011;10:61-75.

6. Eriksson BI, Borris LC, Dahl OE, et al; ODIXa-hip study investigators. Oral, direct factor Xa inhibition with BAY 59-7939 for the prevention of venous thromboembolism after total hip replacement. J Thromb Haemost. 2006;4:121-8.

7. Turpie AG, Fisher WD, Bauer KA, et al; ODIXa-knee study group. BAY 59-7939: an oral, direct factor Xa inhibitor for the prevention of venous thromboembolism in patients after total knee replacement. A phase II dose-ranging study. J Thromb Haemost. 2005;3:2479-86.

8. Eriksson BI, Borris LC, Dahl OC, et al; ODIXa-hip study investigators. A once-daily, oral, direct Factor Xa inhibitor, rivaroxaban (BAY 59-7939), for thromboprophylaxis after total hip replacement. Circulation. 2006;114:2374-81. 
9. Eriksson BI, Borris LC, Friedman RJ, et al; RECORD1 study group. Rivaroxaban versus enoxaparin for thromboprophylaxis after hip arthroplasty. N Engl J Med. 2008;358:2765-75.

10. Kakkar AK, Brenner B, Dahl OE, et al; RECORD2 investigators. Extended duration rivaroxaban versus short-term enoxaparin for the prevention of venous thromboembolism after total hip arthroplasty: a double-blind, randomised controlled trial. Lancet. 2008;372:31-9.

11. Lassen MR, Ageno W, Borris LC, et al; RECORD3 investigators. Rivaroxaban versus enoxaparin for thromboprophylaxis after total knee arthroplasty. N Engl J Med. 2008;358:2776-86.

12. Turpie AG, Lassen MR, Davidson BL, et al; RECORD4 investigators. Rivaroxaban versus enoxaparin for thromboprophylaxis after total knee arthroplasty (RecoRd4): a randomised trial. Lancet. 2009;9676:1673-80.

13. Agnelli G, Gallus A, Goldhaber SZ, et al; ODIXa-DVT study investigators. Treatment of proximal deep-vein thrombosis with the oral direct factor Xa inhibitor rivaroxaban (BAY 59-7939): the ODIXa- DVT (oral direct factor Xa inhibitor BAY 59-7939 in patients with acute symptomatic deep-vein thrombosis) study. Circulation. 2007;116:180-7.

14. Buller HR, Lensing AW, Prins MH, et al; EINSTEIN-DVT Dose-Ranging Study investigators. A dose-ranging study evaluating once-daily oral administration of the factor Xa inhibitor rivaroxaban in the treatment of patients with acute symptomatic deep vein thrombosis. The EINSTEIN- DvT Dose-Ranging Study. Blood. 2008;112:2242-7.

15. EINSTEIN investigators, Bauersachs R, Berkowitz SD, Brenner $\mathrm{B}$, et al. Oral rivaroxaban for symptomatic venous thromboembolism. N Engl J Med. 2010;363:2499-510.

16. The EINSTEIN-PE investigators. Oral rivaroxaban for the treatment of symptomatic pulmonary embolism. N Engl J Med. 2012;366:1287-97.

17. Romualdi E, Donadini MP, Ageno W. Oral rivaroxaban after symptomatic venous thromboembolism: the continued treatment study (EINSTEIN-extension study). Expert Rev Cardiovasc Ther. 2011;9:841-4.

18. Patel MR, Mahaffey KW, Garg J, et al; ROCKET AF investigators. Rivaroxaban versus warfarin in nonvalvular atrial fibrillation. N Engl J Med. 2011;365:883-91.

19. Hori M, Matsumoto M, Tanahashi N, et al. Rivaroxaban vs. warfarin in Japanese patients with atrial fibrillation. Circ J. 2012;76:2104-11. 
20. Mega JL, Braunwald E, Mohanavelu S, et al; ATLAS ACS-TIMI 46 study group. Rivaroxaban versus placebo in patients with acute coronary syndromes (ATLAS ACS-TIMI 46): a randomised, double-blind, phase II trial. Lancet. 2009;374:29-38.

21. Mega JL, Braunwald E, Wiviott SD, et al; ATLAS ACS 2-TIMI 51 Investigators. Rivaroxaban in patients with a recent acute coronary syndrome. N Engl J Med. 2012;366:9-19.

22. Cohen AT, Spiro TE, Büller HR, et al. Extended-duration rivaroxaban thromboprophylaxis in acutely ill medical patients: MAGELLAN study protocol. J Thromb Thrombolysis. 2011; 31:407-16.

23. Cohen AT, Spiro TE, Büller HR, et al. Rivaroxaban for thromboprophylaxis in acutely ill medical patients. $\mathrm{N}$ Engl $\mathbf{J}$ Med. 2013;368:513-23.

24. Eriksson BI, Borris LC, Dahl OE, et al. Dose-escalation study of rivaroxaban (BAY 59-7939) - an oral, direct factor Xa inhibitor - for the prevention of venous thromboembolism in patients undergoing total hip replacement. Thromb Res. 2007;120: 685-93.

25. Fisher WD, Eriksson BI, Bauer KA, et al. Rivaroxaban for thromboprophylaxis after orthopaedic surgery: pooled analysis of two studies. Thromb Haemost. 2007;97:931-7.

26. Shantsila E, Lip GY. Apixaban, an oral, direct inhibitor of activated factor Xa. Curr Opin Investig Drugs. 2008;9:1020-33.

27. Lassen MR, Davidson BL, Gallus A, Pineo G,Ansell J, Deitchman D. The efficacy and safety of apixaban, an oral, direct factor Xa inhibitor, as thromboprophylaxis in patients following total knee replacement. J Thromb Haemost. 2007;5:2368-75.

28. Lassen MR, Raskob GE, Gallus A, Pineo G, Chen D, Portman RJ. Apixaban or enoxaparin for thromboprophylaxis after knee replacement. N Engl J Med. 2009;36:594-604.

29. Lassen MR, Raskob GE, Gallus A, et al; ADVANCE-2 Investigators. Apixaban versus enoxaparin for thromboprophylaxis after knee replacement (ADVANCE-2): a randomised double-blind trial. Lancet. 2010;375:807-15.

30. Lassen MR, Gallus A, Raskob GE, et al; ADVANCE-3 Investigators. Apixaban versus enoxaparin for thromboprophylaxis after hip replacement. N Engl J Med. 2010;363:2487-98.

31. Botticelli Investigators, Writing Committee, Buller H, Deitchman D, Prins M, et al. Efficacy and safety of the oral direct factor Xa inhibitor apixaban for symptomatic deep vein thrombosis. The Botticelli DVT dose-ranging study. J Thromb Haemost. 2008;6:1313-8. 
32. Agnelli G, Büller HR, Cohen A, et al. Oral apixaban for the treatment of acute venous thromboembolism. N Engl J Med. 2013;369:799-808.

33. Agnelli G, Buller HR, Cohen A, et al. Apixaban for extended treatment of venous thromboembolism. $N$ Engl J Med. 2013;368:699-708.

34. Connolly SJ, Eikelboom J, Joyner C, et al; AVERROES steering committee and investigators. Apixaban in patients with atrial fibrillation. N Engl J Med. 2011;364:806-17.

35. Granger CB, Alexander JH, McMurray JJ, et al; ARISTOTLE committees and investigators. Apixaban versus warfarin in patients with atrial fibrillation. N Engl J Med. 2011;365:981-92.

36. APPRAISE Steering Committee and Investigators, Alexander JH, Becker RC, Bhatt DL, et al. Apixaban, an oral, direct, selective factor Xa inhibitor, in combination with antiplatelet therapy after acute coronary syndrome: results of the Apixaban for Prevention of Acute Ischemic and Safety Events (APPRAISE) trial. Circulation. 2009;119:2877-85.

37. APPRAISE-2 Investigators, Alexander JH, Lopes RD, James S, et al. Apixaban with antiplatelet therapy after acute coronary syndrome. N Engl J Med. 2011;365:699-708.

38. Goldhaber SZ, Leizorovicz A, Kakkar AK, et al; Adopt trial investigators. Apixaban versus enoxaparin for thromboprophylaxis in medically ill patients. N Engl J Med. 2011;365:2167-77.

39. Levine $\mathrm{MN}, \mathrm{Gu} \mathrm{C}$, Liebman $\mathrm{HA}$, et al. A randomized phase II trial of apixaban for the prevention of thromboembolism in patients with metastatic cancer. J Thromb Haemost. 2012;10:807-14.

40. Furugohri T, Isobe K, Honda Y, et al. DU-176b, a potent and orally active factor Xa inhibitor: in vitro and in vivo pharmacological profiles. J Thromb Haemost. 2008;6:1542-9.

41. Wolzt M, Samama MM, Kapiotis S, Ogata K, Mendell J, Kunitada S. Effect of edoxaban on markers of coagulation in venous and shed blood compared with fondaparinux. Thromb Haemost. 2011;105:1080-90.

42. Mendell J, Chen S, He L, Desai M, Parasrampuria D. The effect of rifampin on the pharmacokinetics (PK)and pharmacodynamics (PD) of edoxaban in healthy subjects. J Thromb Haemost. 2014;12(Suppl 1):Abstract COA26.

43. Zahir H, Matsushima N, Halim AB, et al. Edoxaban administration following enoxaparin: a pharmacodynamic, pharmacokinetic, and tolerability assessment in human subjects. Thromb Haemost. 2012;108:166-75. 
44. Bathala MS, Masumoto H, Oguma T, He L, Lowrie C, Mendell J. Pharmacokinetics, biotransformation, and mass balance of edoxaban, a selective, direct factor Xa inhibitor, in humans. Drug Metab Dispos. 2012;40:2250-5.

45. Koretsune Y, Yamashita T, Yasaka M. Evaluation of edoxaban in patients with atrial fibrillation and severe renal impairment. Eur Heart J. 2013;34(Suppl 1):abstract P520.

46. Mendell J, Shi M. Safety, tolerability, pharmacokinetic (PK) and pharmacodynamic (PD) profiles of edoxaban in healthy postmenopausal or surgically sterile females, and healthy elderly males. Eur Heart J. 2011;32(Suppl 1):abstract P2614.

47. Daiichi Sankyo Europe GmbH. LIXIANA ${ }^{\circledR}$ European Summary of Product Characteristics 2015. http://www.ema.europa.eu/ema/ index.jsp?curl=pages/medicines/human/medicines/002629/ human_med_001874.jsp\&mid=WC0b01ac058001d124.

48. Perosphere, Inc. Effects of a double-blind, single dose of PER977 administered alone, and following a single dose of edoxaban (PER977-P1). (clinicaltrials.gov identifier NCT01826266). US National Institutes of Health, clinicaltrials.gov. Available at: www.clinicaltrials.gov. Accessed 20 Nov 2014.

49. Ansell JE, Bakhru SH, Laulicht BE, et al. Use of PER977 to reverse the anticoagulant effect of edoxaban. N Engl J Med. 2014; [Epub ahead of print]. DOI: 10.1056/NEJMc1411800.

50. Perosphere, Inc. Study of PER977 administered to subjects with steady state edoxaban dosing and re-anticoagulation with edoxaban (clinicaltrials.gov identifier NCT02207257). US National Institutes of Health, clinicaltrials.gov. Available at: www.clinicaltrials.gov. Accessed 21 Nov 2014.

51. U.S. FDA Approves Daiichi Sankyo's Once-Daily SAVAYSA ${ }^{\mathrm{TM}}$ (edoxaban) tablets for reduction of stroke risk in non-valvular atrial fibrillation and for the treatment of venous thromboembolism. Available at: www.daiichisankyo.com. Accessed 15 Jan 2015.

52. Daiichi Sankyo's Once-Daily LIXIANA® (edoxaban) Approved in the EU for stroke prevention in nonvalvular atrial fibrillation and for the treatment and prevention of recurrent DVT and PE. Available at: www.daiichisankyo.com. Accessed 01 July 2015.

53. Fuji T, Fujita S, Tachibana S, Kawai Y. A dose-ranging study evaluating the oral factor Xa inhibitor edoxaban for the prevention of venous thromboembolism in patients undergoing total knee arthroplasty. J Thromb Haemost. 2010;8:2458-68. 
54. Raskob G, Cohen AT, Eriksson BI, et al. Oral direct factor Xa inhibition with edoxaban from thromboprophylaxis after elective total hip replacement. Thromb Haemost. 2010;104:642-9.

55. Fuji T, Wang CJ, Fujita S, et al. Edoxaban versus enoxaparin for thromboprophylaxis after total knee arthroplasty: The stars E-3 trial. Pathophysiol Haemos Thromb. 2009-2010;37:131-158 OC297.

56. Fujita S, Fuji T, Tachibana S, Nakamura M, Kawai Y. Safety and efficacy of edoxaban in patients undergoing hip fracture surgery. Pathophysiol Haemos Thromb. 2009-2010;37:P366.

57. Fuji T, Fujita S, Tachibana S, et al. Efficacy and safety of edoxaban versus enoxaparin for the prevention of venous thromboembolism following total hip arthroplasty: STARS J-V trial. Blood. 2010;116:Abstract 3320.

58. Weitz JI, Connolly SJ, Patel I, et al. Randomised, parallel-group, multicentre, multinational phase 2 study comparing edoxaban, an oral factor $\mathrm{Xa}$ inhibitor, with warfarin for stroke prevention in patients with atrial fibrillation. Thromb Haemost. 2010;104:633-41.

59. Ruff CT, Giugliano RP, Antman EM, et al. Evaluation of the novel factor $\mathrm{Xa}$ inhibitor edoxaban compared with warfarin in patients with atrial fibrillation: design and rationale for the Effective aNticoaGulation with factor xA next GEneration in Atrial Fibrillation-Thrombolysis In Myocardial Infarction study 48 (ENGAGE AF-TIMI 48). Am Heart J. 2010;160:635-41.

60. Giugliano RP, Ruff CT, Braunwald E, et al. Edoxaban versus warfarin in patients with atrial fibrillation. $\mathrm{N}$ Engl $\mathrm{J}$ Med. 2013;369:2093-104.

61. Raskob G, Büller H, Prins M, et al. Edoxaban for the long-term treatment of venous thromboembolism: rationale and design of the Hokusai-venous thromboembolism study--methodological implications for clinical trials. J Thromb Haemost. 2013;11:1287-94.

62. Hokusai-VTE investigators, Büller $\mathrm{H}$, Decousus $\mathrm{H}$, et al. Edoxaban versus warfarin for the treatment of symptomatic venous thromboembolism. N Engl J Med. 2013;369:1406-15.

63. Kuroda Y, Hirayama C, Hotoda H, Nishikawa Y, Nishiwaki A. Postmarketing safety experience with edoxaban in Japan for thromboprophylaxis following major orthopedic surgery. Vasc Health Risk Manag. 2013;9:593-8.

64. Salazar DE, Mendell J, Kastrissios H, et al. Modelling and simulation of edoxaban exposure and response relationships in patients with atrial fibrillation. Thromb Haemost. 2012;107: 925-36. 
65. Turpie AG, Bauer KA, Davidson BL, et al; EXPERT Study Group. A randomized evaluation of betrixaban, an oral factor $\mathrm{Xa}$ inhibitor, for prevention of thromboembolic events after total knee replacement (EXPERT). Thromb Haemost. 2009;101: 68-76.

66. Connolly SJ, Eikelboom J, Dorian P, et al. Betrixaban compared with warfarin in patients with atrial fibrillation: results of a phase 2, randomized, dose-ranging study (Explore-Xa). Eur Heart J. 2013;34:1498-505.

67. Eriksson BI, Dahl OE, Lassen MR, Ward DP, Rothlein R, Davis G, Turpie AGG. Partial factor IXa inhibition with TTP889 for prevention of venous thromboembolism: an exploratory study. J Thromb Haemost. 2008;6:457-63.

68. Green Cross Corporation. A study to access safety, tolerability, Pharmacokinetics(PK) and Pharmacodynamics(PD) of orally administered GCC-4401C in healthy volunteers (clinicaltrials. gov identifier NCT01954238). US National Institutes of Health, clinicaltrials.gov. Available at: www.clinicaltrials.gov. Accessed 21 Nov 2014.

69. Portola Pharmaceuticals. Acute medically ill VTE prevention with extended duration Betrixaban Study (The APEX Study). (clinicaltrials.gov identifier NCT01583218). US National Institutes of Health, clinicaltrials.gov. Available at: www.clinicaltrials.gov. Accessed 20 Nov 2014.

70. Cohen AT, Harrington R, Goldhaber SZ, Hull R, Gibson CM, Hernandex AF, Kitt MM, Lorenz TJ. The design and rationale for the Acute Medically Ill Venous Thromboembolism Prevention with Extended Duration Betrixaban (APEX) study. Am Heart J. 2014;167:335-41.

71. Eikelboom JW, Zelenkofske SL, Rusconi CP. Coagulation factor IXa as a target for treatment and prophylaxis of venous thromboembolism. Arterioscler Thromb Vasc Biol. 2010;30:382-7. 


\section{Chapter 4 Conclusions}

The number of available NOACs has provided clinicians with a greater range of options for the management of patients with thromboembolic disorders. Recently, two meta-analyses compared the efficacy and safety of the NOACs in stroke prevention in patients with AF [1] and the prevention of recurrent venous thromboembolism (VTE) [2]. These metaanalyses were the first to include data for all four NOACs studied in pivotal phase III studies for these indications.

In the meta-analysis of patients with AF, this included all 71,683 patients from the RE-LY, ROCKET AF, ARISTOTLE, and ENGAGE AF-TIMI 48 studies; in total 42,411 patients received a NOAC and 29,272 patients received warfarin. Treatment with NOACs was associated with a $19 \%$ decrease in the risk of stroke compared with warfarin (relative risk 0.81, $95 \%$ CI 0.73-0.91; $\mathrm{P}<0.0001$ ) (Fig. 4.1).

In patients treated with NOACs, there was a significant reduction in all-cause mortality (relative risk $0.90,95 \% \mathrm{CI}$ 0.85-0.95; $\mathrm{P}=0.0003$ ) and intracranial bleeding (relative risk $0.48,95 \%$ CI $0.39-0.59 ; \mathrm{P}<0.0001$ ), however an increase in gastrointestinal bleeding was noted (relative risk 1.25, $95 \%$ CI 1.01-1.55; $\mathrm{P}=0.043$ ). Low-dose NOAC regimens exhibited similar rates of stroke and systemic embolic events to warfarin (relative risk 1.03, $95 \% \mathrm{CI} 0.84-1.27 ; \mathrm{P}=0.74$ ), with a more favorable bleeding profile (relative risk $0.65,95 \% \mathrm{CI}$ $0.43-1.00 ; \mathrm{P}=0.05)$ but were associated with significantly 


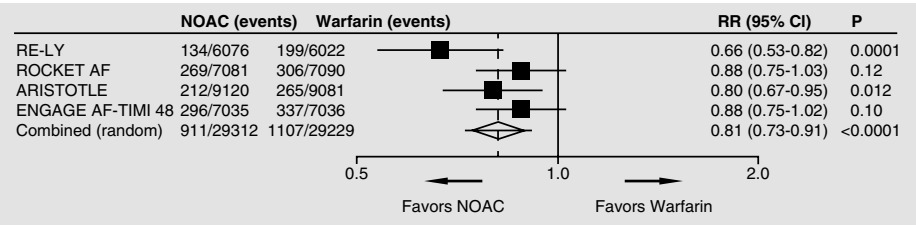

FIgURE 4.I Stoke or systemic embolic events. $C I$ confidence interval, NOAC non-VKA oral anticoagulants, $R R$ relative risk (Reproduced with permission from Ruff et al. [1])

more ischemic strokes (relative risk 1.28, 95 \% CI 1.02-1.60; $\mathrm{P}=0.045)$. NOACs were associated with a favorable riskbenefit profile compared with warfarin, having demonstrated significant reductions in stroke, intracranial hemorrhage and mortality and similar rates of major bleeding. The safety and efficacy outcomes of NOACs in AF are consistent across a wide range of patients.

A similar meta-analysis based on phase III trials comparing NOACs to VKAs in 24,455 patients with VTE was performed, which included five studies, RE-COVER, EINSTEIN-DVT, EINSTEIN-PE, AMPLIFY and HokusaiVTE. The risk ratios for VTE, fatal pulmonary embolism and overall mortality for NOACs vs VKAs were 0.88 (95\% CI 0.74-1.05), 1.02 (95\% CI 0.39-5.96), and 0.97 (95\% CI 0.83-1.14), respectively (Fig. 4.2).

With regards to safety the risk ratio of major bleeding was 0.60 (95\% CI 0.41-0.88) and fatal bleeding 0.36 (95\% CI 0.15-0.87). Compared with VKAs, in the treatment of VTE NOACs have comparable efficacy with a significantly lower risk of bleeding complications.

\subsection{Future Directions}

The number of NOACs that have been approved or are under clinical development reflects the huge clinical demand for such medicines and the desire of the pharmaceutical industry to respond to the as yet unmet needs of patients. 


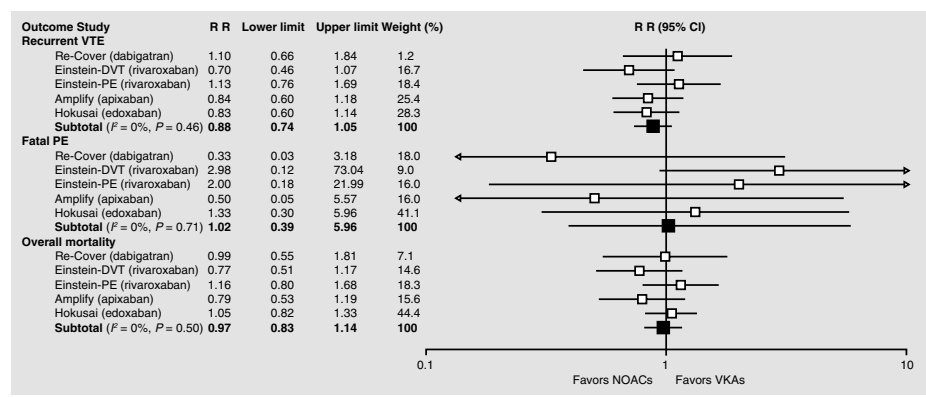

Figure 4.2 Efficacy outcomes of non-VKA oral anticoagulants (NOACs) vs vitamin K antagonists (VKAs) in phase III prevention of venous thromboembolism (VTE) studies. $C I$ confidence interval, $P E$ pulmonary embolism, $R R$ relative risk (Reproduced with permission from van der Hulle et al. [2])

Four NOACs, the direct thrombin inhibitor dabigatran etexilate and the direct factor Xa inhibitors rivaroxaban, apixaban and edoxaban, have already successfully completed phase III trials for indications requiring long-term anticoagulation. These drugs largely correspond to the requirements of an ideal anticoagulant. Furthermore, as they all participate in late stages of the coagulation cascade, their inhibition allows disruption of both the intrinsic and the extrinsic pathways; their high antithrombotic efficacy stems from this 'double' action.

OpenAccess This chapter is distributed under the terms of the Creative Commons Attribution Noncommercial License, which permits any noncommercial use, distribution, and reproduction in any medium, provided the original author(s) and source are credited.

\section{References}

1. Ruff CT, Giugliano RP, Braunwald E, et al. Comparison of the efficacy and safety of new oral anticoagulants with warfarin in patients with atrial fibrillation: a meta-analysis of randomised trials. Lancet. 2014;383:955-62. 


\section{Chapter $4 . \quad$ Conclusions}

2. van der Hulle T, Kooiman J, den Exter PL, Dekkers OM, Klok FA, Huisman MV. Effectiveness and safety of novel oral anticoagulants as compared with vitamin $\mathrm{K}$ antagonists in the treatment of acute symptomatic venous thromboembolism: a systematic review and meta-analysis. J Thromb Haemost. 2014;12:320-8. 